\title{
CB1 Receptor Signaling Modulates Amygdalar Plasticity during Context-Cocaine Memory Reconsolidation to Promote Subsequent Cocaine Seeking
}

\author{
${ }^{\circ}$ Jessica A. Higginbotham, ${ }^{1}$ Rong Wang, ${ }^{1}{ }^{\circledR}$ Ben D. Richardson,,${ }^{1,2,3}{ }^{\circledR}$ Hiroko Shiina, ${ }^{1}$ Shi Min Tan, ${ }^{1}$ \\ Mark A. Presker, ${ }^{4}{ }^{-}$David J. Rossi, ${ }^{1,5}$ and ${ }^{-}$Rita A. Fuchs ${ }^{1,5}$ \\ ${ }^{1}$ Department of Integrative Physiology and Neuroscience, Washington State University College of Veterinary Medicine, Pullman, Washington \\ 99164, ${ }^{2}$ Department of Biological Engineering, University of Idaho, Moscow, Idaho 83844, ${ }^{3}$ WWAMI Medical Education, University of Idaho, \\ Moscow, Idaho 83844, ${ }^{4}$ Department of Psychology and Neuroscience, University of North Carolina, Chapel Hill, North Carolina 27599, and \\ ${ }^{5}$ Washington State University Alcohol and Drug Abuse Research Program, Pullman, Washington 99164
}

Contextual drug-associated memories precipitate craving and relapse in cocaine users. Such associative memories can be weakened through interference with memory reconsolidation, a process by which memories are maintained following memory retrieval-induced destabilization. We hypothesized that cocaine-memory reconsolidation requires cannabinoid type 1 receptor (CB1R) signaling based on the fundamental role of the endocannabinoid system in synaptic plasticity and emotional memory processing. Using an instrumental model of cocaine relapse, we evaluated whether systemic CB1R antagonism (AM251; $3 \mathrm{mg} / \mathrm{kg}$, i.p.) during memory reconsolidation altered (1) subsequent drug context-induced cocaine-seeking behavior as well as (2) cellular adaptations and (3) excitatory synaptic physiology in the basolateral amygdala (BLA) in male Sprague Dawley rats. Systemic CB1R antagonism, during, but not after, cocaine-memory reconsolidation reduced drug context-induced cocaine-seeking behavior $3 \mathrm{~d}$, but not three weeks, later. CB1R antagonism also inhibited memory retrieval-associated increases in BLA zinc finger 268 (zif268) and activity regulated cytoskeletal-associated protein (Arc) immediate-early gene (IEG) expression and changes in BLA AMPA receptor (AMPAR) and NMDA receptor (NMDAR) subunit phosphorylation that likely contribute to increased receptor membrane trafficking and synaptic plasticity during memory reconsolidation. Furthermore, CB1R antagonism increased memory reconsolidation-associated spontaneous EPSC (sEPSC) frequency in BLA principal neurons during memory reconsolidation. Together, these findings suggest that CB1R signaling modulates cellular and synaptic mechanisms in the BLA that may facilitate cocaine-memory strength by enhancing reconsolidation or synaptic reentry reinforcement, or by inhibiting extinction-memory consolidation. These findings identify the CB1R as a potential therapeutic target for relapse prevention.

Key words: amygdala; CB1; cocaine; endocannabinoid; memory reconsolidation; reinstatement

Significance Statement

Drug relapse can be triggered by the retrieval of context-drug memories on re-exposure to a drug-associated environment. Context-drug associative memories become destabilized on retrieval and must be reconsolidated into long-term memory stores to persist. Hence, targeted interference with memory reconsolidation can weaken maladaptive context-drug memories and reduce the propensity for drug relapse. Our findings indicate that cannabinoid type 1 receptor (CB1R) signaling is critical for context-cocaine memory reconsolidation and subsequent drug context-induced reinstatement of cocaine-seeking behavior. Furthermore, cocaine-memory reconsolidation is associated with CB1R-dependent immediate-early gene (IEG) expression and changes in excitatory synaptic proteins and physiology in the basolateral amygdala (BLA). Together, our findings provide initial support for $\mathrm{CB1R}$ as a potential therapeutic target for relapse prevention.

Received June 2, 2020; revised Nov. 16, 2020; accepted Nov. 20, 2020.

Author contributions: J.A.H., B.D.R., M.A.P., D.J.R., and R.A.F. designed research; J.A.H., R.W., B.D.R., H.S., S.M.T., M.A.P., and R.A.F. performed research; J.A.H., B.D.R., H.S., and R.A.F. analyzed data; J.A.H. and R.A.F. wrote the paper.

Acknowledgements: This work was supported by National Institute on Drug Abuse Grants R01 DA025646 (to R.A.F.) and F31 DA 045430 (to J.A.H.), the National Institute on Alcohol Abuse and Alcoholism Grant R01 AA026078 (to D.J.R.), the National Institute of Neurological Disorders and Stroke Grant T32 NS007431 (to
M.A.P.), and Washington State Initiative 171 (J.A.H.) and 502 (to R.A.F.) funds administered through the Washington State University Alcohol and Drug Abuse Research Program.

The authors declare no competing financial interests.

Correspondence should be addressed to Rita A. Fuchs at rita.fuchs@wsu.edu.

https://doi.org/10.1523/JNEUROSCI.1390-20.2020

Copyright $\odot 2021$ the authors 


\section{Introduction}

Exposure to drug-associated environmental stimuli triggers the retrieval of maladaptive drug memories that can precipitate drug craving and relapse in cocaine users (Childress et al., 1988, 1999; Crombag et al., 2008). Like other associative memories, cocaineassociated memories become labile on retrieval (Lee et al., 2005). Retention of destabilized memories requires memory reconsolidation processes that involve de novo protein synthesis (Nader et al., 2000; Fuchs et al., 2009; Wells et al., 2011) and glutamatergic synaptic plasticity (Rao-Ruiz et al., 2015; Rich and Torregrossa, 2018; Rich et al., 2019). Consequently, targeted interference with memory reconsolidation can weaken contextual cocaine-associated memories and reduce the propensity for drug relapse (Fuchs et al., 2009; Ramirez et al., 2009; Wells et al., 2011, 2013, 2016; Arguello et al., 2014; Stringfield et al., 2017). Accordingly, it is important to investigate the cellular mechanisms of cocainememory reconsolidation with a focus on viable therapeutic targets.

Endocannabinoids are primarily retrograde messengers that modulate excitatory and inhibitory synaptic plasticity (Castillo et al., 2012) and some forms of memory reconsolidation through the stimulation of presynaptic cannabinoid type 1 receptors (CB1Rs; for review, see Stern et al., 2018). CB1R antagonism during memory reconsolidation impairs Pavlovian morphine- (De Carvalho et al., 2014), methamphetamine- (Yu et al., 2009), and nicotine- (Fang et al., 2011) conditioned place preference (CPP) memories. However, critical gaps remain in our understanding of CB1R involvement in memory reconsolidation. First, it is unclear whether $\mathrm{CB} 1 \mathrm{Rs}$ regulate the reconsolidation of cocaine memories. Second, it is not known whether CB1Rs play similar roles in the reconsolidation of drug memories forged in instrumental versus Pavlovian paradigms, as extant literature indicates that Pavlovian and instrumental cocaine-associated memories are reconsolidated through partially distinct neural mechanisms (Miller and Marshall, 2005; Théberge et al., 2010; Wells et al., 2013). Finally, the cellular and synaptic physiological mechanisms by which CB1Rs modulate drug-memory reconsolidation have not been explored.

In the present study, we tested the hypothesis that CB1Rs are critically involved in contextual cocaine-memory reconsolidation in an instrumental model of drug relapse. First, we evaluated whether systemic CB1R antagonism during memory reconsolidation impairs cocaine-memory integrity as indicated by a subsequent, memory retrieval-dependent reduction in cocaine-seeking behavior. Second, we assessed the effects of memory reconsolidation and systemic CB1R antagonism on molecular adaptations and excitatory synaptic physiology in the basolateral amygdala (BLA), the critical site for protein synthesis-dependent memory reconsolidation in our model (Fuchs et al., 2009; Wells et al., 2011). It has been established that auditory fear-memory reconsolidation requires memory retrieval-dependent, transient, NMDA receptor (NMDAR)-dependent synaptic exchange of calcium-impermeable (CI; GluA2-containing) AMPARs with calcium-permeable (CP; GluA2-lacking) AMPARs in the lateral amygdala (Clem and Huganir, 2010; Hong et al., 2013; Lopez et al., 2015; Yu et al., 2016). While similar research has not explored the molecular mechanisms of contextual appetitive or aversive memory reconsolidation, we have shown that BLA protein kinase A (PKA) activation is necessary for cocaine-memory reconsolidation in the drug context-induced reinstatement model (Arguello et al., 2014). Other studies have demonstrated that PKA-mediated GluA1 ${ }^{\mathrm{S} 845}$ phosphorylation enhances GluA1 synaptic recruitment (Clem and Huganir, 2010), whereas Src-family tyrosine kinase ( $\mathrm{Src}$ )-mediated GluA2 ${ }^{\mathrm{Y} 876}$ phosphorylation elicits GluA2 endocytosis (Hayashi and Huganir, 2004). Thus, elevated $\mathrm{Ca}^{2+}$ influx through NMDARs activates PKA and Src-tyrosine kinases which promote changes in synaptic AMPAR-subunit composition that collectively mediate expression of long-term potentiation (LTP; He et al., 2009; Makino and Malinow, 2009). Moreover, Src-mediated GluN2B ${ }^{\mathrm{Y} 1472}$ phosphorylation is required for proper GluN2B synaptic localization, signaling, and amygdalar synaptic plasticity, raising another kinase control point for plasticity expression and/or initiation (Nakazawa et al., 2006). Accordingly, in the present study, we identified alterations in immediate-early gene (IEG) expression and in glutamate receptor subunit expression and phosphorylation with a focus on GluA $1^{\text {S845 }}$, GluA2 $2^{\text {Y876, }}$, and GluN2B ${ }^{\text {Y1472 }}$ phosphorylation. To explore the synaptic physiological significance of these posttranslational protein modifications, we determined changes in excitatory post-synaptic currents (EPSCs) in glutamatergic pyramidal principal neurons (PNs) of the BLA.

\section{Materials and Methods}

\section{Animals}

Male Sprague Dawley rats $(n=108 ; 275-300 \mathrm{~g}$ at the start of the experiment) were individually housed in a temperature-controlled and humidity-controlled vivarium on a reversed light/dark cycle (lights on at 6 A.M.). Rats were given ad libitum access to water and 20-25 g of standard rat chow per day. The housing and care of animals were conducted in accordance with guidelines defined in the Guide for the Care and Use of Laboratory Animals (National Research Council, 2011) and approved by the Washington State University Institutional Animal Care and Use Committee.

\section{Food training and surgery}

To facilitate the acquisition of drug self-administration, rats were trained to press a lever (active lever) under a continuous food reinforcement schedule in standard operant conditioning chambers (Coulbourn Instruments) during a $16 \mathrm{~h}$ overnight food training session. Each active-lever response resulted in the unsignaled delivery of one food pellet (45-mg pellets; Bioserv) under a continuous reinforcement schedule. Responses on a second (inactive) lever were recorded but had no programmed consequences. Contextual stimuli used for subsequent cocaine conditioning were not present during the food-training session.

For jugular catheter implantation, rats were fully anesthetized using ketamine hydrochloride and xylazine (100 and $5 \mathrm{mg} / \mathrm{kg}$, i.p., respectively; Dechara Veterinary Products and Akorn) at least $24 \mathrm{~h}$ after food training. Jugular catheters were constructed in house and surgically implanted into the right jugular vein to facilitate cocaine self-administration. The catheters were maintained and periodically tested for patency as described previously (Fuchs et al., 2007). Rats received the non-steroidal anti-inflammatory analgesic, carprofen $(5 \mathrm{~g} / \mathrm{kg} / \mathrm{d}$, p.o.; ClearH2O), from $24 \mathrm{~h}$ before until $48 \mathrm{~h}$ after surgery.

\section{Cocaine self-administration and extinction training}

Rats were randomly assigned to one of two different environmental contexts for cocaine self-administration training. The two environmental contexts contained distinct olfactory, auditory, visual, and tactile stimuli, as previously described (Fuchs et al., 2007). Daily 2-h training sessions were conducted in one of the two environmental contexts during the rats' dark cycle. During training sessions, active-lever responses were reinforced under a fixed ratio 1 cocaine reinforcement schedule $(0.15 \mathrm{mg}$ cocaine hydrochloride/0.05 ml infusion, i.v.; NIDA Drug Supply Program, Research Triangle Park, NC). Cocaine infusions were delivered over $2.25 \mathrm{~s}$ followed by a 20 -s time-out period, during which active-lever responses had no programmed consequences. Inactivelever responses had no programmed consequences. Training continued until the rats reached the acquisition criterion (i.e., $\geq 10$ cocaine 
infusions obtained per session on at least 10 training days). Next, rats received daily 2 -h extinction training sessions in the alternate environmental context, where lever presses had no programmed consequences. The number of extinction sessions was set at seven to hold memory age constant at the time of the experimental manipulation. Immediately after extinction session 4 , the rats received an intraperitoneal injection of saline $(1 \mathrm{ml} / \mathrm{kg})$ to acclimate them to the injection procedure.

Experiment 1: effects of CB1R antagonism immediately after memory retrieval on drug context-induced cocaine seeking 3 dater

Twenty-four $\mathrm{h}$ after the seventh extinction session, rats were re-exposed to the cocaine-paired context for $15 \mathrm{~min}$ (Fig. 1A). This session length is sufficient to trigger memory destabilization without overt extinction learning (Fuchs et al., 2009). During the session, lever presses had no programmed consequences. Cocaine reinforcement was withheld to prevent acute cocaine effects on neurotransmission and endocannabinoid mobilization independent of memory destabilization (Ortinski et al., 2012; Wang et al., 2015). Immediately after the session (i.e., during the putative time of memory reconsolidation), rats received systemic administration of the CB1R antagonist/inverse agonist, $N$-(piperidin-1-yl)5-(4-iodophenyl)-1-(2,4-dichlorophenyl)-4-methyl-1H-pyrazole-3carboxamide (AM251; $3 \mathrm{mg} / \mathrm{kg}$; Sigma-Aldrich), or vehicle (VEH; 8\% DMSO, $5 \%$ Tween 80 in saline; $1 \mathrm{ml} / \mathrm{kg}$ ). AM251 at this dose is sufficient to impair contextual fear learning and memory consolidation (Arenos et al., 2006). Treatment-group assignment was balanced based on activelever responses and cocaine intake during the last three training sessions. On the next day, daily 2 -h extinction training sessions resumed in the designated extinction context until the rats reached the extinction criterion (i.e., $\leq 25$ active-lever presses/session on two consecutive days; mean number of days to criterion $=2.0 \pm 0.0 \mathrm{~d}$ ). Lever responses in the extinction context were assessed to detect possible offtarget effects of experimental manipulations on extinction memories. Twenty-four $h$ after the last extinction session, cocaine-seeking behavior (i.e., non-reinforced lever responses) was assessed in the cocainepaired context. Rats were euthanized 1-2 min after the 2-h test session through rapid decapitation in experiments $1-4$. In experiment 1 , brains were flash frozen in isopentane and stored for analysis of BLA IEG and glutamate-receptor subunit expression using Western blotting, as described below. Based on the phosphorylation kinetics of glutamate receptor subunits (Clem and Huganir, 2010; Rao-Ruiz et al., 2011), these tissue samples were prepared and analyzed for total-protein levels only.

Experiment 2: effects of $C B 1 R$ antagonism 6 h after memory retrieval on drug context-induced cocaine seeking 3 d later

Memory reconsolidation impairments require manipulation while the memories are labile (i.e., 2-4 h after memory retrieval; Tronson and Taylor, 2007). Experiment 2 evaluated whether any impairments in cocaine-seeking behavior in experiment 1 reflected a memory reconsolidation deficit (Fig. 2A) as opposed to prolonged impairment in the expression of cocaine-seeking behavior. The procedures in experiment 2 were identical to those in experiment 1 except that rats received AM251 $(3 \mathrm{mg} / \mathrm{kg}$, i.p.) or VEH $6 \mathrm{~h}$ after the 15 -min memory retrieval session in the cocaine-paired context, outside of the putative time window of memory reconsolidation. As in experiment 1, daily 2-h extinction training sessions resumed in the extinction context after the memory retrieval session until the extinction criterion was reached (mean number of days to criterion $=2.00 \pm 0.0 \mathrm{~d}$ ). The extinction sessions were followed by a single 2 -h test of cocaine-seeking behavior in the cocaine-paired context. Rats were euthanized immediately after the test session. Their brains were flash frozen in isopentane and stored for analysis of BLA IEG and glutamate receptor subunit expression using Western blotting, as in experiment 1.

Experiment 3: effects of CB1R antagonism immediately after memory retrieval on drug context-induced cocaine seeking $24 d$ later

Experiment 3 assessed whether any effects of AM251 on memory integrity persisted over time. The procedures were identical to those in experiment 1 except that, after memory retrieval and pharmacological manipulation, rats remained in their home cages for $21 \mathrm{~d}$ (Fig. $3 A$ ). Daily 2-h extinction training sessions then resumed until the extinction criterion was reached (mean number of days to criterion $=2.93 \pm$ $0.27 \mathrm{~d}$ ), and this was followed by a 2-h test of cocaine-seeking behavior (i.e., $24 \mathrm{~d}$ posttreatment). Rats were euthanized immediately after the test session. Their brains were flash frozen in isopentane and stored for analysis of BLA IEG and glutamate-receptor subunit expression using Western blotting, as in experiment 1 .

\section{Experiment 4: effects of memory reconsolidation and $C B 1 R$ antagonism} on BLA protein expression and phosphorylation

Experiment 4 evaluated memory reconsolidation-related changes in IEG expression and glutamate-receptor subunit expression and phosphorylation. The procedures in experiment 4 were identical to those in experiment 1 except that rats were euthanized $45 \mathrm{~min}$ after memory retrieval or no-memory retrieval (home-cage stay) and pharmacological treatment (Fig. 4A). This euthanasia time point was selected based on the activation kinetics of activity-regulated cytoskeletal-associated protein (Arc) and zinc finger 268 (zif268; Lee et al., 2004; Li et al., 2005) and associated changes in glutamate-receptor expression and phosphorylation in other models of synaptic plasticity (Clem and Huganir, 2010; Rao-Ruiz et al., 2011). The brains were flash frozen in isopentane and stored for analysis of BLA IEG and glutamate-receptor subunit expression and glutamate-receptor subunit phosphorylation using Western blotting.

\section{Western blotting}

Brains were stored at $-80^{\circ} \mathrm{C}$ before the collection of BLA tissue punches (o.d. $0.75 \mathrm{~mm}$ ). Punched tissue was stored at $-80^{\circ} \mathrm{C}$ in lysis buffer containing $10 \mathrm{~mm}$ HEPES, $1 \%$ SDS, and $1 \times$ protease and phosphatase inhibitor cocktails (Sigma-Aldrich). Samples were thawed, manually homogenized, and total tissue homogenate protein concentrations were determined using the Biorad detergent-compatible protein assay $\left(R^{2} \geq 0.99\right)$. After electrophoresis and transfer, membranes were dried overnight at $4^{\circ} \mathrm{C}$. The next day, membranes were reactivated in methanol and blocked before incubation overnight in Odyssey blocking buffer (Li-Cor Biosciences) with $0.2 \%$ Tween 20 and primary antibodies targeting Arc (catalog \#sc-17839, RRID:AB_626696), zif268 (catalog \#sc-189, RRID: AB_2231020), NMDAR subunit 2B (GluN2B; catalog \#06-600, RRID:AB_310193), phospho-Tyr ${ }^{1472}$-GluN2B (pGluN2B; catalog \#p1516-1472, RRID:AB_2492182), GluA1 (catalog \#sc-13152, RRID: AB_627932), phospho-Ser ${ }^{8 \overline{4}}$-GluA1 (pGluA1; catalog \#AB5849, RRID: AB_92079), GluA2 (catalog \#MABN1189, RRID:AB_2737079), phospho$\mathrm{Tyr}^{876}$-GluA2 (pGluA2; catalog \#4027, RRID:AB_1147622), calnexin (CNX; catalog \#ADI-SPA-860, RRID:AB_10616095), or glyceraldehyde-3-phosphate dehydrogenase (GAPDH; catalog \#ab8245, RRID:AB_2107448). Membranes were then washed and incubated for $1 \mathrm{~h}$ in Odyssey blocking buffer with $0.2 \%$ Tween 20 and $0.01 \%$ SDS with the following near-infrared fluorescent secondary antibodies: IRDye $800 \mathrm{CW}$ goat anti-mouse (catalog \#926-32210, RRID:AB_621842), IRDye 800CW goat anti-rabbit (catalog \#926-32211, RRID:AB_621843), IRDye 680RD donkey anti-mouse (catalog \#926-68072, RRID:AB_10953628), and IRDye 680LT goat anti-rabbit (catalog \#926-68021, RRID:AB_10706309). For multiplexed targets (based on antibody availability), the $800-\mathrm{nm}$ channel was used to detect the lowest-abundance, phospho-proteins as it provides lower background, maximizing detection sensitivity (SchutzGeschwender et al., 2004). Total proteins were detected in the $680-\mathrm{nm}$ channel. Membranes were digitally imaged using a Li-Cor Odyssey CLX. Integrated optical intensity values for target protein bands were derived using Li-Cor Image Studio Software (RRID: SCR_015795) by experimenters blinded to treatment condition. Total protein levels were normalized to a loading control and expressed as a percentage of the comparator group (experiments 1-3: VEH treated; experiment 4 (Fig. 5): VEH-nomemory retrieval). Phospho-specific values were normalized to total protein values. A lane-normalization factor was calculated for the total and house-keeping proteins by dividing the lane's integrated optical intensity value by the highest signal value on the blot. Target-protein integrated intensity values were divided by the respective loading control's lane-normalization factor to normalize signal values across blots (SchutzGeschwender et al., 2004). 
A

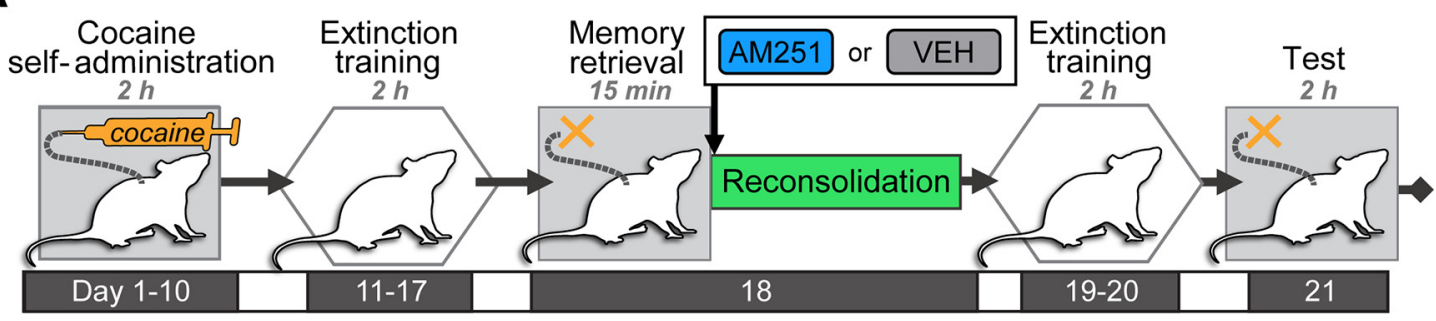

B
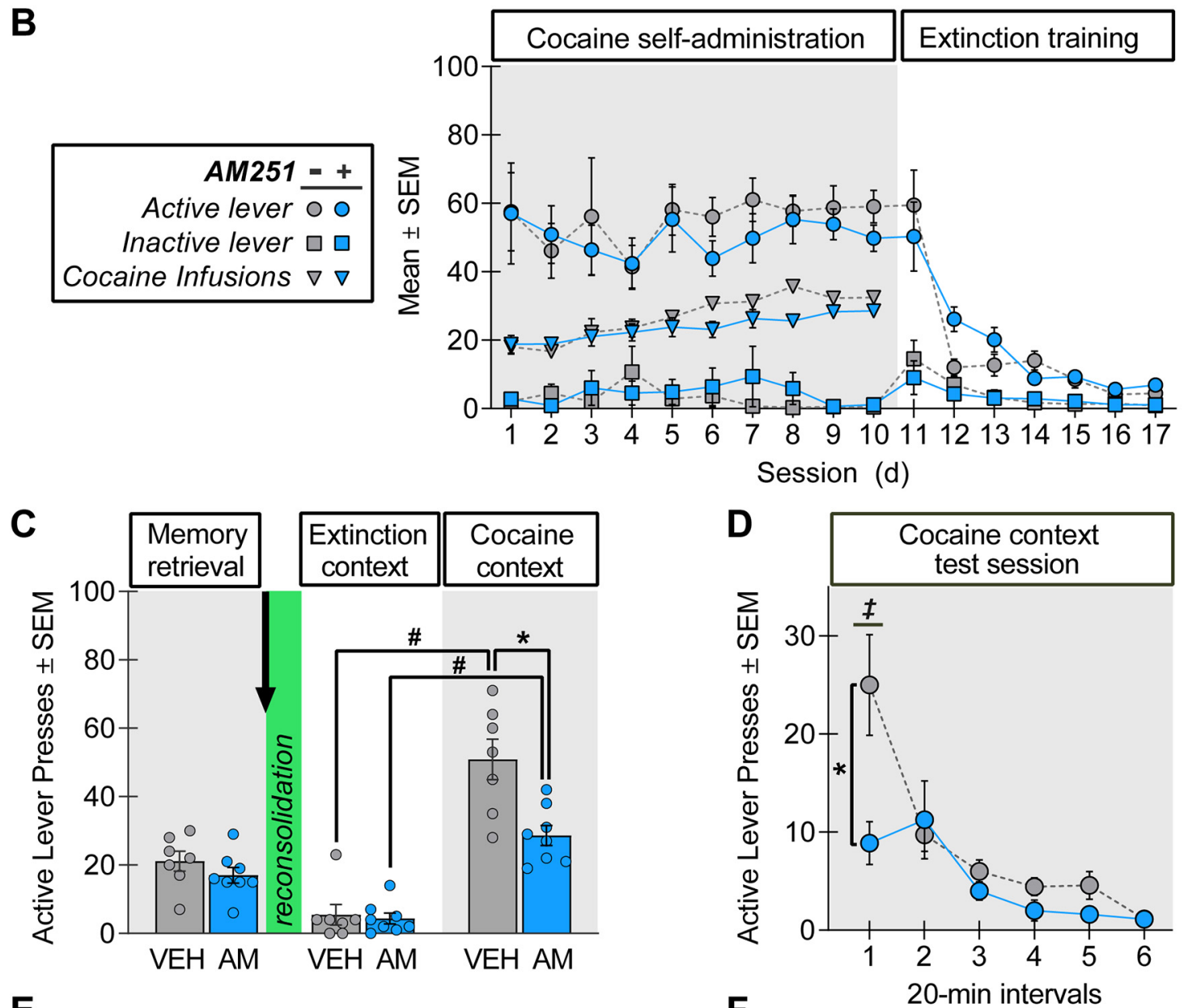

E

F
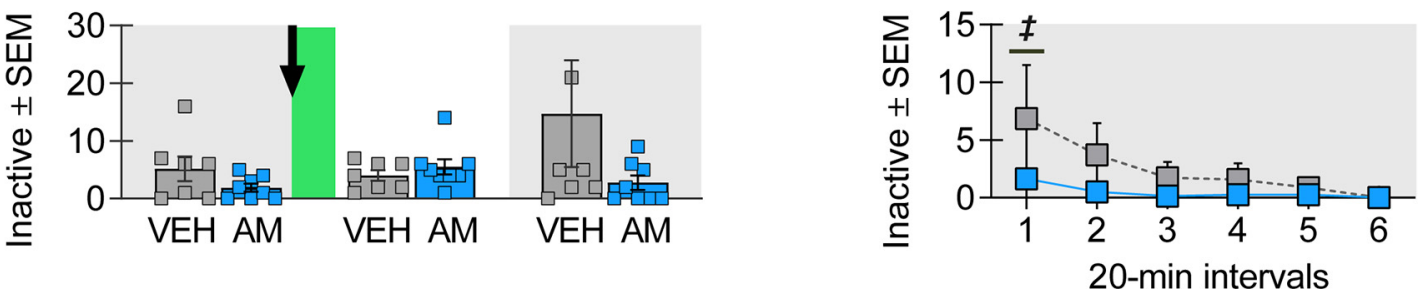

Figure 1. Systemic AM251 administration during memory reconsolidation reduces drug context-induced cocaine-seeking behavior $3 \mathrm{~d}$ later. $\boldsymbol{A}$, Experimental timeline. The 15 -min memoryretrieval session was immediately followed by systemic AM251 (AM251; $3 \mathrm{mg} / \mathrm{kg}$, i.p.; $n=8$ ) or VEH ( $n=7$ ) administration. After at least two additional daily extinction sessions, drug-seeking behavior was assessed in the cocaine-paired context. $\boldsymbol{B}$, Lever responses and cocaine infusions during drug self-administration (last $10 \mathrm{~d}$ ) and extinction training. $\boldsymbol{C}$, Active-lever responses during the memory retrieval session in the cocaine-paired context before treatment (arrow) and on first re-exposure to the extinction context and the cocaine-paired context at test. $\boldsymbol{D}$, Time course of active-lever responses in the cocaine-paired context at test. $\boldsymbol{E}$, Inactive-lever responses during the memory retrieval session in the cocaine-paired context before treatment (arrow) and on first re-exposure to the extinction context and the cocaine-paired context at test. $\boldsymbol{F}$, Time course of inactive-lever responses in the cocaine-paired context at test. Symbols: ANOVA \#context simple main effect, Sidak's test, $p<0.05$; *treatment simple main effect, Sidak's test, $p<0.05$ (C), Tukey's test, $p<0.05$ (D); łtime simple main effects (VEH: interval $1>2-6$; AM251: intervals $1-2>4-6)$, Tukey's tests, $p s<0.05$. 
A

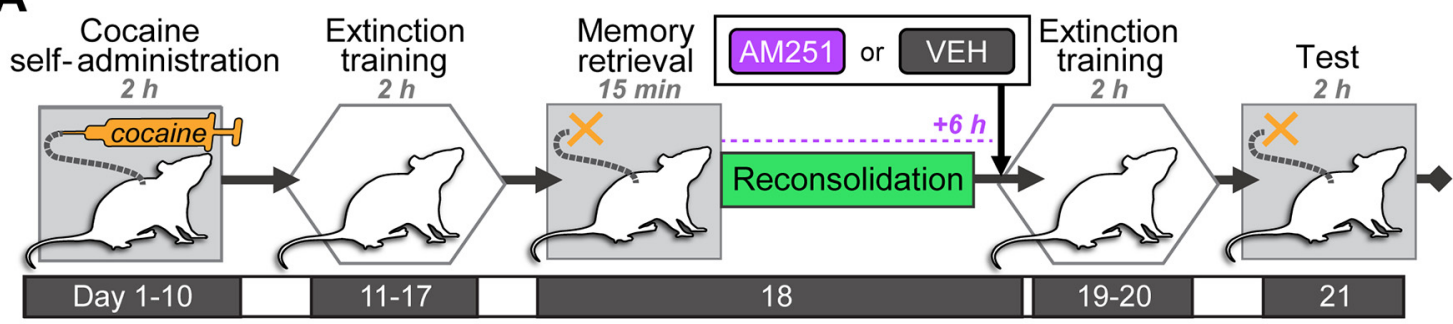

B

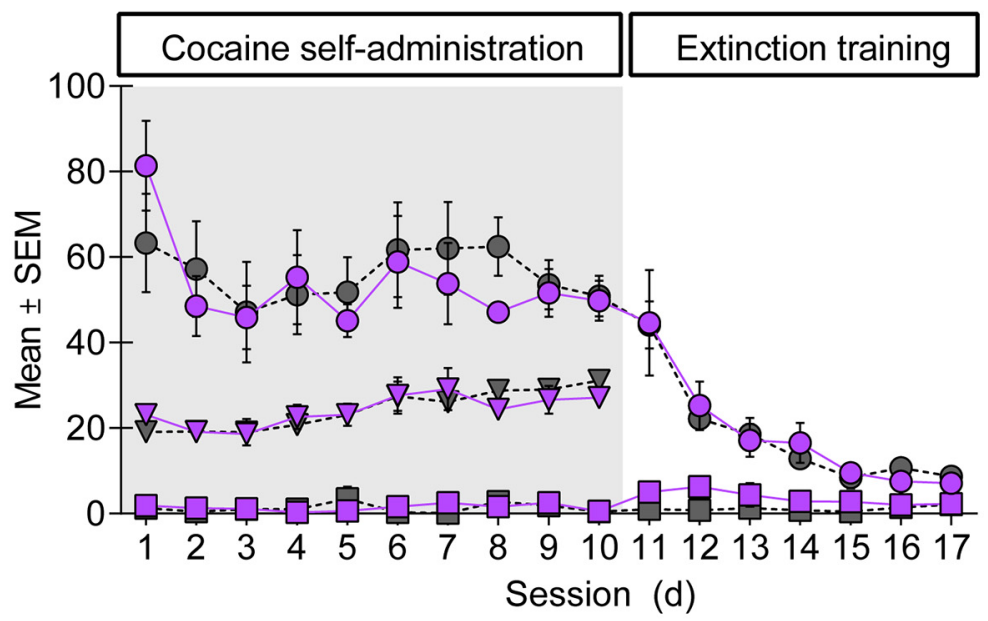

C

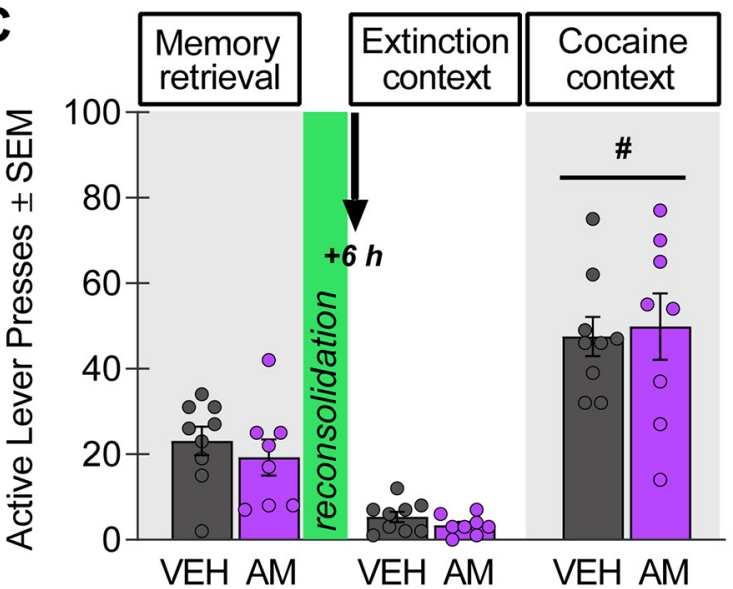

D

Active lever $\bigcirc \bigcirc$

Inactive lever $\square \square$

Cocaine Infusions $\nabla \nabla$

Session (d)

E

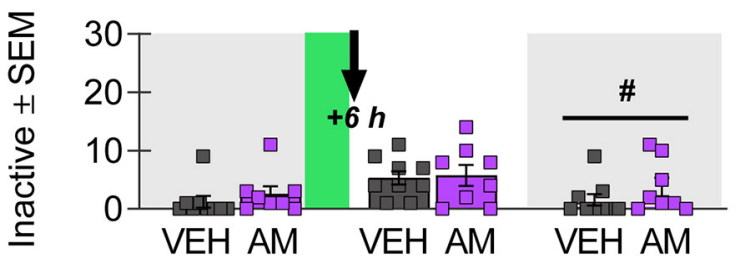

F

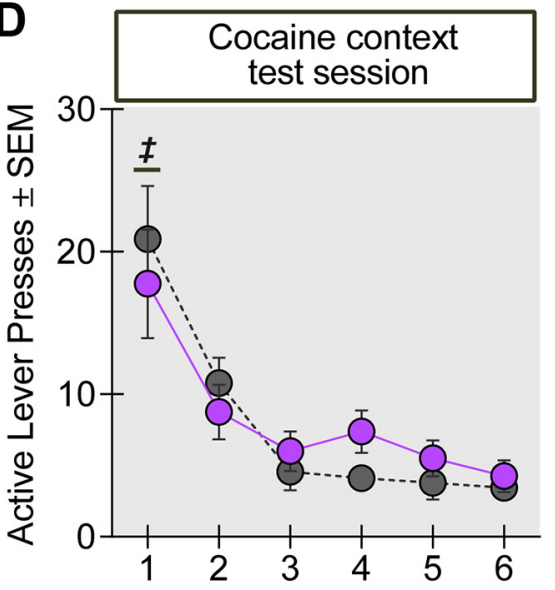

20-min intervals

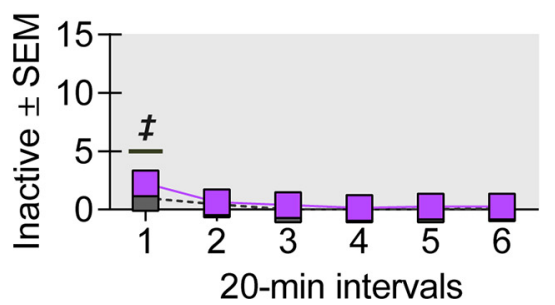

Figure 2. Systemic AM251 administration after memory reconsolidation fails to alter context-induced cocaine-seeking behavior $3 \mathrm{~d}$ later. $A$, Experimental timeline. The 15 -min memory-retrieval session was followed by systemic AM251 (AM251; $3 \mathrm{mg} / \mathrm{kg}$, i.p.; $n=8$ ) or VEH $(n=9)$ administration $6 \mathrm{~h}$ later (i.e., outside of the memory reconsolidation window). After at least two additional daily extinction sessions with $\leq 25$ active-lever responses, drug-seeking behavior was assessed in the cocaine-paired context. $\boldsymbol{B}$, Lever responses and cocaine infusions during drug self-administration and extinction training. C, Active-lever responses during the memory retrieval session in the cocaine-paired context before treatment (arrow) and on first re-exposure to the extinction context and the cocaine-paired context at test. $\boldsymbol{D}$, Time course of active-lever responses across in the cocaine-paired context at test. Omnibus ANOVA effects are reported in Results. $\boldsymbol{E}$, Inactive-lever responses during the memory retrieval session in the cocaine-paired context before treatment (arrow) and on first re-exposure to the extinction context and the cocaine-paired context at test. $\boldsymbol{F}$, Time course of inactive-lever responses in the cocaine-paired context at test. Symbols: ANOVA \#context main effect, $p<0.05$; \#time simple main effects (interval $1>2-6$ ), Tukey's tests, ps $<0.05$. 
A

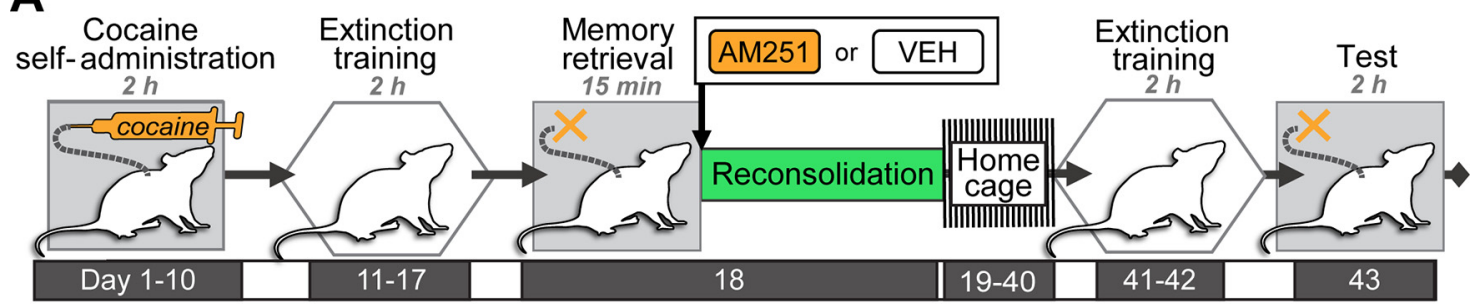

B
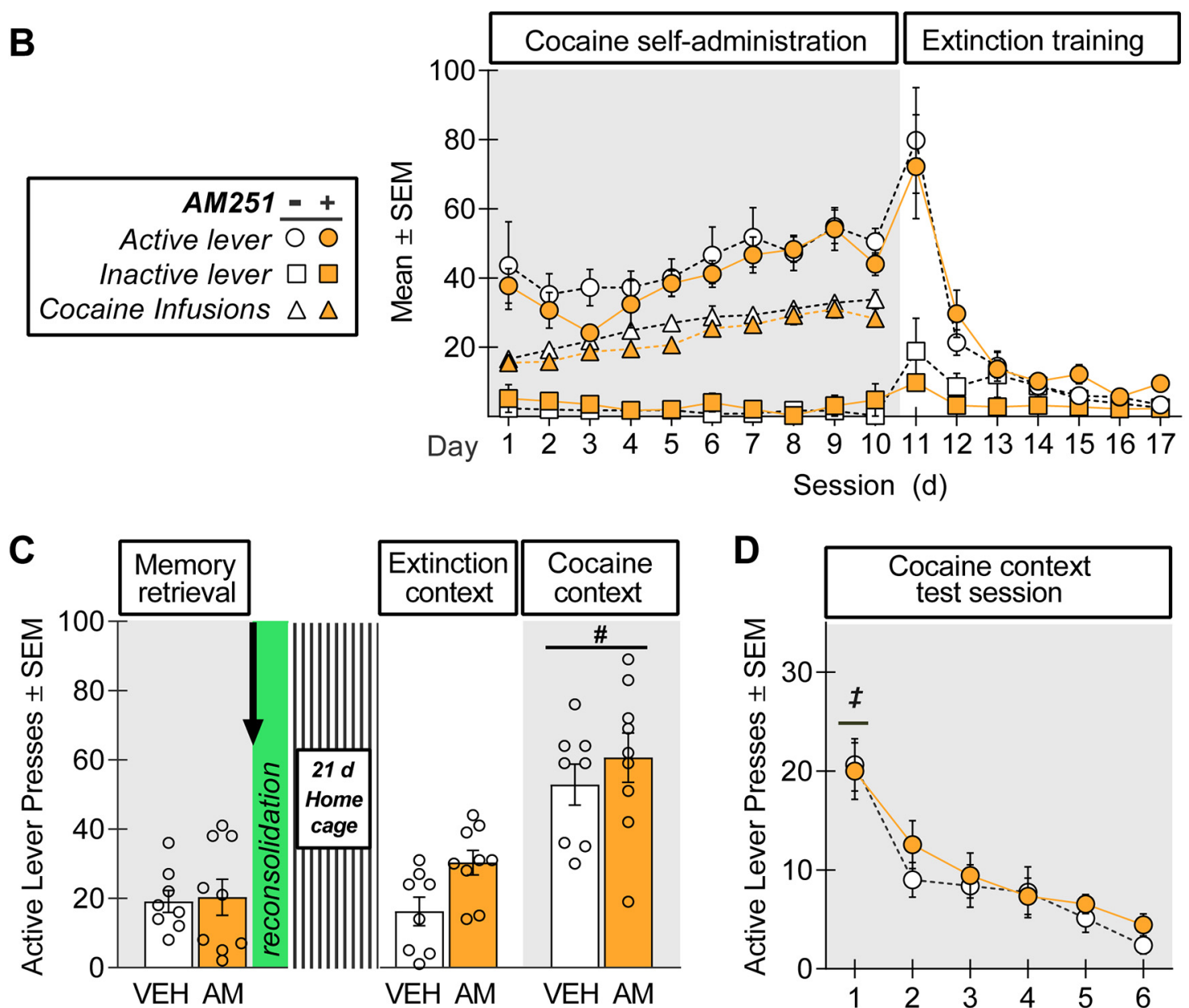

Inactive lever $\square \square$

Cocaine Infusions $\Delta \Delta$

\section{E}

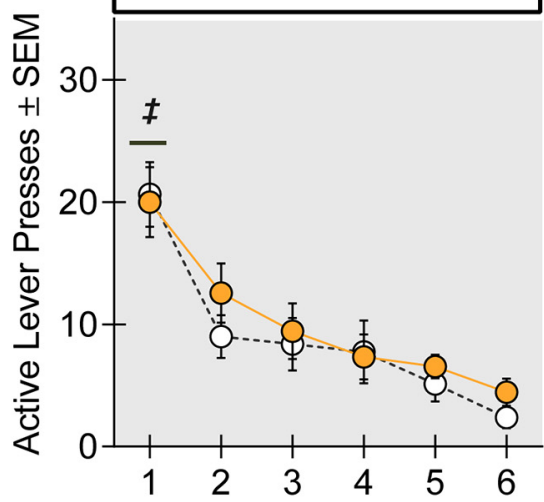

$\mathbf{F}$

20-min intervals
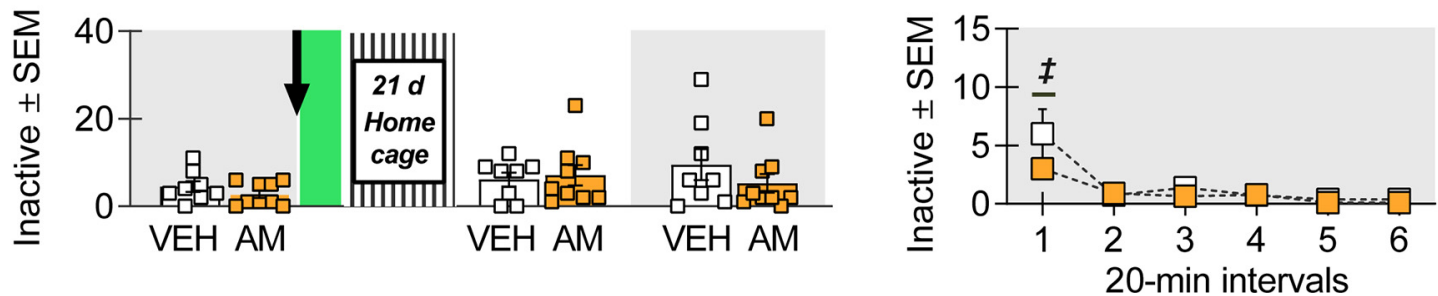

Figure 3. Systemic AM251 administration during memory reconsolidation does not alter drug context-induced cocaine-seeking behavior $24 \mathrm{~d}$ later. $\boldsymbol{A}$, Experimental timeline. The 15 -min memory-retrieval session was immediately followed by systemic administration of AM251 (AM251; $3 \mathrm{mg} / \mathrm{kg}$, i.p.; $n=9$ ) or VEH $(n=8)$. After $21 \mathrm{~d}$ of home cage stay, rats received at least two additional daily extinction sessions with $\leq 25$ active-lever responses before the test of drug-seeking behavior in the cocaine-paired context. $\boldsymbol{B}$, Lever responses and cocaine infusions during drug self-administration and extinction training. $\boldsymbol{C}$, Active-lever responses during the memory-retrieval session in the cocaine-paired context before treatment (arrow) and after treatment followed by $21 \mathrm{~d}$ of home cage stay, on first re-exposure to the extinction context and the cocaine-paired context at test. $\boldsymbol{D}$, Time course of active-lever responses in the cocaine-paired context at test. $\boldsymbol{E}$, Inactive-lever responses during the memory retrieval session in the cocaine-paired context before treatment (arrow) and on first re-exposure to the extinction context and the cocainepaired context at test. $\boldsymbol{F}$, Time course of inactive-lever responses in the cocaine-paired context at test. Symbols: ANOVA \#context main effect, $p<0.05$; ¥time simple main effects (interval $1>2-6)$, Tukey's tests, $p s<0.05$. 

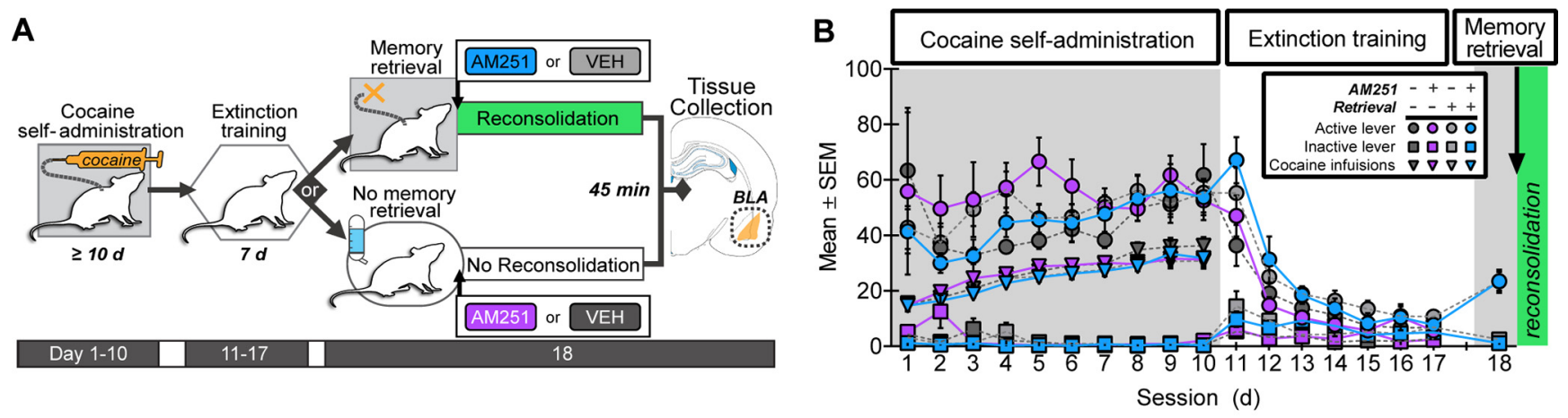

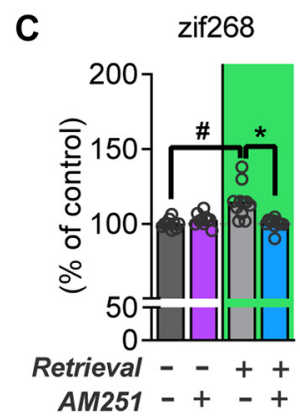

H

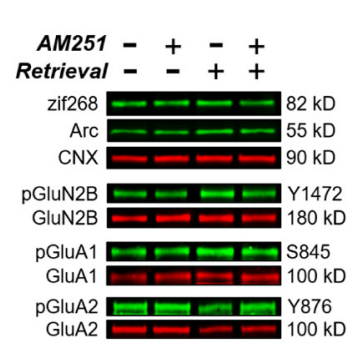

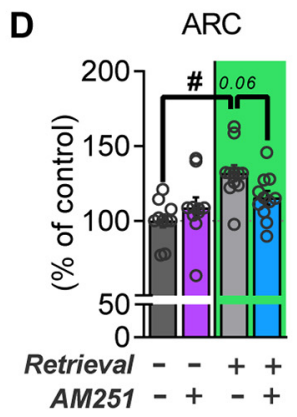

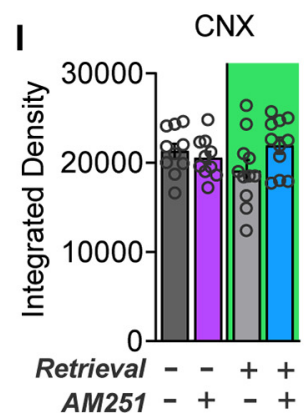

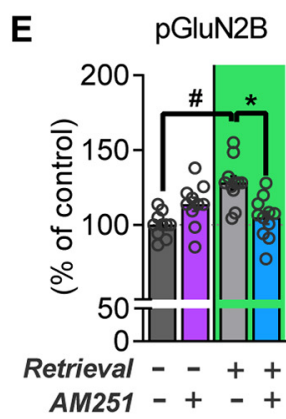

$\mathbf{J}$

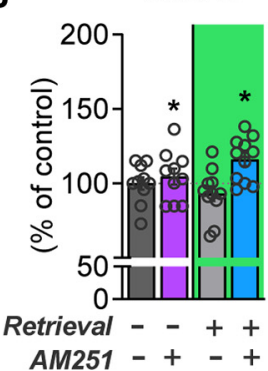

$\mathbf{F}$

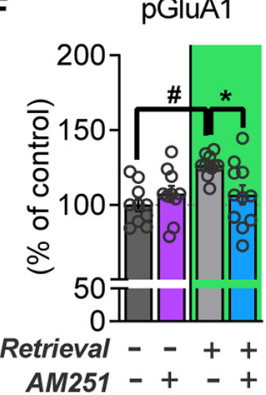

K

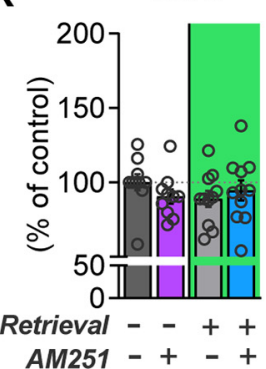

G

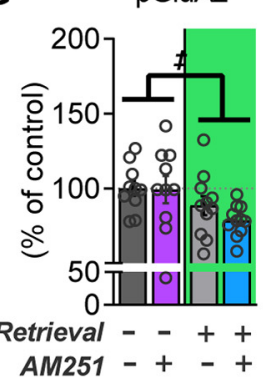

$\mathbf{L}$

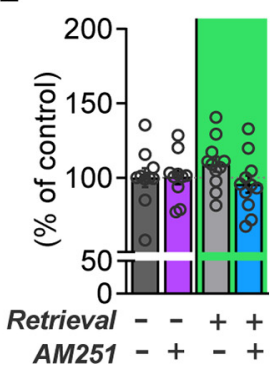

Figure 4. Systemic AM251 administration after memory retrieval prevents changes in BLA IEG expression and glutamate receptor subunit phosphorylation during memory reconsolidation. $A$, Experimental timeline. Systemic AM251 (3 mg/kg, i.p.) or VEH was administered immediately after cocaine-memory retrieval or no-memory retrieval ( $n=10-11$ per group). BLA tissue samples were collected $45 \mathrm{~min}$ later for analysis of full tissue homogenates. $\boldsymbol{B}$, Lever responses and cocaine infusions during cocaine self-administration, extinction training, and the 15-min memory retrieval session. Mean $\boldsymbol{C}$, zif268 and $\boldsymbol{D}$, ARC levels normalized to the loading control, CNX. Mean levels of $\boldsymbol{E}$, GluN2B phosphorylation at Y1472 (pGluN2B), $\boldsymbol{F}$, GluA1 phosphorylation at S845 (pGluA1), and G, GluA2 phosphorylation at Y876 (pGluA2) normalized to total protein levels. $\boldsymbol{H}$, Composite image of representative Western blottings. I, Mean CNX (loading control) integrated density values. J, GluN2B, $\boldsymbol{K}$, GluA1 and $\boldsymbol{L}$, GluA2 levels normalized to CNX. Values are expressed as a percentage of the no-memory retrieval VEH control group. Symbols: ANOVA, \#retrieval simple main effect, Sidak's test, $p<0.05$; *treatment simple main effect, Sidak's test, $p<0.05$ or treatment main effect $(\boldsymbol{J}), p<0.05$; łretrieval main effect, $p<0.05$.

Experiment 5: effects of postretrieval CB1R antagonism on excitatory synaptic transmission in BLA PNs at memory reconsolidation

Experiment 5 examined the effects of memory reconsolidation and systemic CB1R antagonism on glutamatergic EPSCs in BLA PNs, the primary output neurons of the BLA (McDonald, 1984). The procedures in experiment 5 were identical to those in experiment 1 except that rats were exposed to the cocaine-paired context for $15 \mathrm{~min}$ (memory retrieval) or remained in their home cages (no-memory retrieval) before systemic AM251 (3 mg/kg, i.p.) or VEH administration (Fig. 6A).

\section{BLA brain slice electrophysiology}

All rats used for electrophysiological recordings were deeply anesthetized with isoflurane $(3 \%-5 \%)$. Rats were transcardially perfused with icecold artificial CSF (aCSF), which contained $124 \mathrm{~mm} \mathrm{NaCl}, 26 \mathrm{~mm}$ $\mathrm{NaHCO}_{3}, 2.5 \mathrm{~mm} \mathrm{KCl}, 2.5 \mathrm{~mm} \mathrm{CaCl}, 2 \mathrm{~mm} \mathrm{MgCl}, 1 \mathrm{~mm} \mathrm{NaH}{ }_{2} \mathrm{PO}_{4}$, $10 \mathrm{~mm}$ D-glucose, and $1 \mathrm{~mm}$ kynurenic acid, and was bubbled with 95\% $\mathrm{O}_{2} / 5 \% \mathrm{CO}_{2}$ ( $\mathrm{pH}$ 7.4). After perfusion, the brain was rapidly removed and sliced coronally $(225 \mu \mathrm{m})$ in ice-cold dissection buffer $(220 \mathrm{~mm}$ sucrose, $26 \mathrm{~mm} \mathrm{NaHCO}_{3}, 2 \mathrm{~mm} \mathrm{KCl}, 0.5 \mathrm{~mm} \mathrm{CaCl}_{2}, 5 \mathrm{~mm} \mathrm{MgCl}_{2}, 1.25 \mathrm{~mm}$ $\mathrm{NaH}_{2} \mathrm{PO}_{4}, 2 \mathrm{~mm}$ Na-pyruvate, $1 \mathrm{~mm}$ ascorbic acid, $10 \mathrm{~mm}$ D-glucose, and $1 \mathrm{~mm}$ kynurenic acid) bubbled with $95 \% \mathrm{O}_{2} / 5 \% \mathrm{CO}_{2}$. Tissue slices containing the BLA were incubated in room temperature aCSF (with
$1 \mathrm{~mm}$ kynurenic acid) until used. All experiments were conducted within $4 \mathrm{~h}$ of slice preparation.

Slices were transferred to a recording chamber and continually perfused ( $\sim 5 \mathrm{ml} / \mathrm{min}$ ) in aCSF (without kynurenic acid) at a bath temperature of $32-35^{\circ} \mathrm{C}$. All pharmacological agents were dissolved in aCSF and were applied via bath perfusion. BLA pyramidal PNs were visually identified using differential interference contrast imaging through an Olympus $60 \times(0.9 \mathrm{NA})$ water-immersion objective. Whole-cell patchclamp recordings were made by experimenters blinded to treatment condition using glass pipettes with a resistance of 2-3 $\mathrm{M} \Omega$ when filled with internal solution that contained $130 \mathrm{~mm} \mathrm{CsCl}, 4 \mathrm{~mm} \mathrm{NaCl}, 0.5 \mathrm{~mm}$ $\mathrm{CaCl}_{2}, 10$ mм HEPES, 5 mм EGTA, 4 mм Mg-ATP, 0.5 mм Na 2 -GTP, 5 mm QX-314, $0.1 \mathrm{~mm}$ spermine, and $0.03 \mathrm{~mm}$ Alexa Fluor 568 hydrazide dye with $\mathrm{pH}$ adjusted to $7.2-7.3$ with $\mathrm{CsOH}$. Cells were voltage-clamped at -60 or $+30 \mathrm{mV}$. Signals were digitized at $20 \mathrm{kHz}$, low-pass filtered at $10 \mathrm{kHz}$, and additionally filtered at $2 \mathrm{kHz}$ for presentation. To evoke EPSCs (eEPSCs), a concentric bipolar stimulating electrode was placed into the internal capsule (IC). Once stable whole-cell recording was achieved, the IC was electrically stimulated $(0.1 \mathrm{~ms}$ in duration). Stimulation intensity was gradually increased from zero to determine the minimum stimulus intensity $(20-50 \mu \mathrm{A})$ that elicited a stable synaptic response. Upon achieving a stable synaptic response, the IC was 
stimulated at $0.1 \mathrm{~Hz}$, and 10 synaptic responses were recorded in each pharmacological condition. Glutamatergic eEPSCs were pharmacologically isolated using $1 \mu \mathrm{M}$ strychnine and $10 \mu \mathrm{M}$ gabazine to block glycine and $\mathrm{GABA}_{\mathrm{A}}$ receptors, respectively. AMPAR-mediated eEPSCs were isolated by adding $50 \mu \mathrm{M}$ D-2-amino-5-phosphonovalerate (AP5), a broadspectrum NMDAR antagonist. For each condition, the 10 eEPSCs were averaged, and their mean amplitudes were analyzed with pClamp software (RRID: SCR_011323). In the absence of AP5, NMDAR-mediated eEPSCs were measured $\left(\mathrm{V}_{\mathrm{h}}=+30 \mathrm{mV}\right)$ as the average amplitude of the EPSC $50 \mathrm{~ms}$ after the onset of the stimulus, when AMPAR-mediated contributions are negligible (Fig. 6C). AMPA/NMDA ratios were calculated as the average inward peak current amplitude $\left(\mathrm{V}_{\mathrm{h}}=-60 \mathrm{mV}\right)$ divided by the outward current amplitude $\left(\mathrm{V}_{\mathrm{h}}=+30 \mathrm{mV}\right)$ at $50 \mathrm{~ms}$ after the onset of the stimulus. The rectification index of the AMPAR eEPSC was calculated as the average peak eEPSC amplitude at $-60 \mathrm{mV}$ divided by the average peak eEPSC amplitude at $+30 \mathrm{mV}$, both recorded in the presence of AP5 to pharmacologically isolate the AMPAR component of the eEPSC. Spontaneous EPSCs (sEPSCs) from at least $300 \mathrm{~s}$ long whole-cell recordings in each condition were analyzed with MiniAnalysis Program software. sEPSCs were detected automatically with an amplitude detection threshold of $2.5 \times$ the amplitude of the peak to peak of the noise (Richardson and Rossi, 2017) and visually confirmed by experimenters blinded to treatment condition. Frequency and mean peak amplitude at -60 and $+30 \mathrm{mV}$ were measured.

\section{Experimental design and statistical analysis}

To identify potential preexisting group differences in behavioral and drug history, active-lever and inactive-lever presses and cocaine intake during drug self-administration training (last three sessions) and non-reinforced lever presses during extinction training (first seven extinction sessions) and during the memory-retrieval session were analyzed using separate mixed-factorial or univariate ANOVAs with subsequent treatment group as the between-subjects factor and time (session) as the within-subject factor, or between-subjects $t$ tests, where appropriate. Non-reinforced lever presses during the first posttreatment exposure to the extinction context and to the cocaine context were analyzed using mixed-factorial ANOVAs with memory retrieval (retrieval, no-memory retrieval) and treatment (AM251, VEH) as between-subjects factors and context (extinction, cocaine-paired) and time (20-min interval) as withinsubjects factors, where appropriate. For experiment 1-3, normalized total protein levels at test were analyzed using $t$ tests. For experiments 4-5, phospho-protein levels, total protein levels, peak and mean eEPSC amplitudes, and sEPSC frequency at memory reconsolidation were analyzed using separate ANOVAs with treatment and memory retrieval as between-subjects factors. Significant interactions and main effects were further analyzed using Sidak's or Tukey's post hoc tests. Cumulative probability distributions of sEPSC amplitudes and interevent intervals across groups (memory retrieval or no-memory retrieval, with AM251 or VEH) were analyzed using non-parametric Kruskal-Wallis tests with Dunn's post hoc tests. Normality and homogeneity of variance were evaluated using Shapiro-Wilk and Maunchly's tests, respectively. The relationships between active-lever presses and total protein levels at test were analyzed using Pearson's $r$ correlational coefficients. Alpha was set at 0.05 for all analyses. Estimated effect sizes for $\mathrm{F}, \mathrm{H}$, and $\mathrm{t}$ statistics are reported based on calculated partial $\eta^{2}\left(\eta_{\mathrm{P}}^{2}\right), \eta^{2}$ for $\mathrm{H}\left(\eta^{2}{ }_{[\mathrm{H}]}\right)$, and Hedge's $g$ values, respectively. Analyses were conducted using SPSS Statistics version 24.0 and GraphPad Prizm version 6.0.

\section{Results}

\section{Behavioral and drug history}

There were no statistically significant differences between the groups in cocaine intake during drug self-administration training or in lever responding during drug self-administration training, extinction training, or memory retrieval in experiments $1-5$ (Figs. $1 B-3 B, 6 B$; Table 1). The data of rats that exhibited catheter failure or inability to reach the acquisition criterion within 21 daily training sessions were excluded from all data analyses.
Experiment 1: systemic CB1R antagonism during memory reconsolidation attenuates subsequent drug context-induced cocaine seeking

Systemic AM251 administration immediately after the 15-min cocaine-memory retrieval session (i.e., at the onset of memory reconsolidation) attenuated cocaine-seeking behavior at test in a context-dependent manner $(2 \times 2$ ANOVA treatment $\times$ context interaction, $F_{(1,13)}=10.93, p=0.006, \eta_{\mathrm{P}}^{2}=0.45$; treatment main effect, $F_{(1,13)}=8.95, p=0.01, \eta_{\mathrm{P}}^{2}=0.40$; context main effect, $F_{(1,13)}=111.80, p=0.0001, \eta_{\mathrm{P}}^{2}=0.90$; Fig. $\left.1 C\right)$. Thus, active-lever responding in the cocaine-paired context was greater than in the extinction context (Sidak's test, $p=0.05$ ). Furthermore, AM251 administered immediately after memory retrieval attenuated active-lever responding in the cocaine-paired context (Sidak's test, $p=0.05$ ), but not the extinction context, relative to $\mathrm{VEH}$. Time course analysis of active-lever presses in the cocaine-paired context revealed that AM251 reduced active-lever responding in a time-dependent manner $(2 \times 6$ ANOVA treatment $\times$ time interaction, $F_{(5,65)}=4.11, p=0.003, \eta_{\mathrm{P}}^{2}=0.24$; treatment main effect $F_{(1,13)}=11.86, p=0.004, \eta_{\mathrm{P}}^{2}=0.48$; time main effect, $F_{(5,65)}=14.59, p=0.0001, \eta_{\mathrm{P}}^{2}=0.53$; Fig. $\left.1 D\right)$. Specifically, post hoc comparisons indicated that active-lever responding declined over time (intervals $1>$ intervals $2-6$, Tukey's tests, $p<0.05$ ), and AM251 reduced responding during the first 20-min interval relative to VEH (Tukey's tests, $p<0.05$ ). Inactive-lever responding remained low in both contexts independent of treatment $(2 \times 2$ ANOVA treatment $\times$ context interaction, $F_{(1,13)}=1.87, p=0.20$, $\eta_{\mathrm{P}}^{2}=0.13$; context main effect, $F_{(1,13)}=3.44, p=0.09, \eta_{\mathrm{P}}^{2}=0.21$; treatment main effect, $F_{(1,13)}=1.88, p=0.19, \eta_{\mathrm{P}}^{2}=0.13$; Fig. $\left.1 E\right)$. Time course analysis confirmed that inactive-lever responding declined across time $\left(2 \times 6\right.$ ANOVA time main effect only, $F_{(5,65)}=$ 2.71, $p=0.03, \eta_{\mathrm{P}}^{2}=0.17$, intervals $1>$ intervals $2-6$, Tukey's post hoc tests, $p<0.05$; Fig. $1 F$ ) independent of treatment (treatment $\times$ time interaction, $F_{(5,65)}=1.07, p=0.38, \eta_{\mathrm{P}}^{2}=0.08$; treatment main effect $\left.F_{(1,13)}=1.88, p=0.19, \eta_{\mathrm{P}}^{2}=0.13\right)$.

\section{Experiment 2: systemic CB1R antagonism outside of the memory reconsolidation window does not alter subsequent drug context-induced cocaine seeking}

Systemic AM251 administration $6 \mathrm{~h}$ after cocaine-memory retrieval (i.e., after reconsolidation into long-term memory stores) did not alter subsequent cocaine-seeking behavior relative to $\mathrm{VEH}\left(2 \times 2\right.$ ANOVA context main effect only, $F_{(1,15)}=89.43$, $p<0.0001, \eta_{\mathrm{P}}^{2}=0.86$; treatment $\times$ context interaction, $F_{(1,15)}=$ $0.21, p=0.66, \eta_{\mathrm{P}}^{2}=0.01$; treatment main effect, $F_{(1,15)}=0.002$, $p=0.97, \eta_{\mathrm{P}}^{2}<0.0001$; Fig. $\left.2 C\right)$. Thus, active-lever responding in the cocaine-paired context was higher than in the extinction context regardless of treatment, and delayed AM251 administration did not alter responding in either context relative to VEH. The time course analysis of active-lever presses in the cocaine-paired context confirmed that AM251 did not alter responding $(2 \times 6$ ANOVA time main effect only, $F_{(5,75)}=20.45, p<0.0001, \eta_{\mathrm{P}}^{2}=$ 0.02 ; treatment $\times$ time interaction, $F_{(5,75)}=0.88, p=0.50, \eta_{\mathrm{P}}^{2}=$ 0.06 ; treatment main effect, $F_{(1,15)}=0.06, p=0.82, \eta_{\mathrm{P}}^{2}=0.004$; Fig. 2D). Post hoc comparisons indicated that active-lever responding declined after the first 20-min interval independent of treatment (interval $1>$ intervals $2-6$, Tukey's tests, $p<0.05$ ). Inactive-lever responding remained low in both contexts independent of treatment $(2 \times 2$ ANOVA context $\times$ treatment interaction, $F_{(1,15)}=3.10, p=0.10, \eta_{\mathrm{P}}^{2}=0.17$; context main effect, $F_{(1,15)}=2.24, p=0.16, \eta_{\mathrm{P}}^{2}=0.13$; treatment main effect, $F_{(1,15)}=$ $0.26, p=0.60, \eta_{\mathrm{P}}^{2}=0.02$; Fig. $\left.2 E\right)$. Time course analysis confirmed that inactive-lever responding declined across time $(2 \times 6$ 
Table 1. Behavioral history

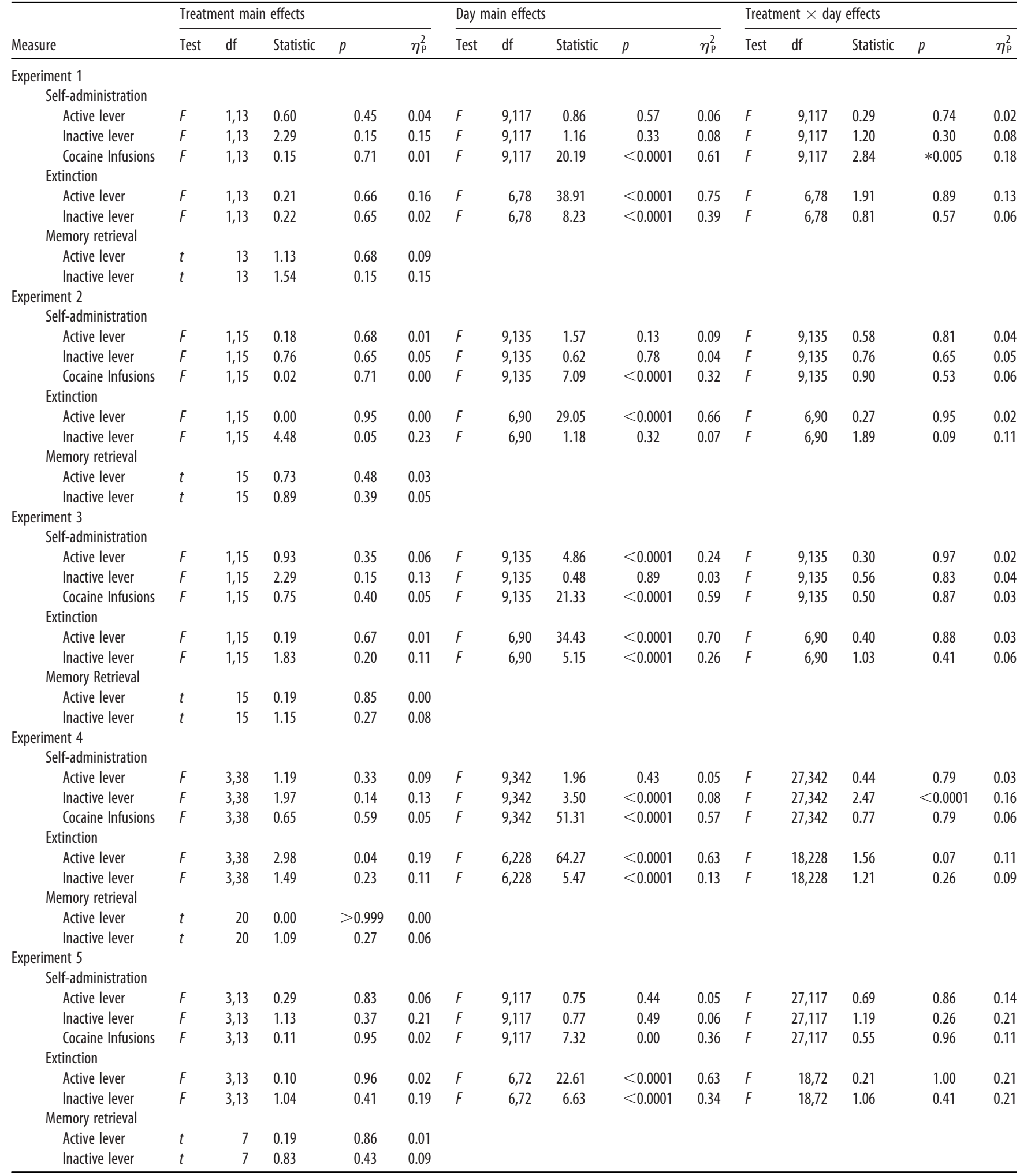

Effects of future group assignment and time (day) on active-lever and inactive-lever responding and drug infusions during cocaine self-administration training (last 10 daily sessions), on active-lever and inactive-lever responding during extinction training (seven daily sessions), and on active-lever and inactive-lever responding during the 15-min memory retrieval session (if applicable) in experiments 1 (Fig. 1B,C), 2 (Fig. 2B,C), 3 (Fig. 3B, C), 4 (Fig. $4 B$ ), and 5 (Fig. 6B). Data shown are ANOVA effects, effect sizes, and the results of post hoc comparisons; * indicates significant group difference, Tukey's post hoc test result.

ANOVA time main effect only, $F_{(5,75)}=7.35, p<0.0001, \eta_{\mathrm{P}}^{2}=$ 0.33 , intervals $1>$ intervals $2-6$, Tukey's post hoc tests, $p<0.05$; Fig. $2 F$ ) independent of treatment (treatment $\times$ time interaction, $F_{(5,75)}=0.96, p=0.44, \eta_{\mathrm{P}}^{2}=0.06$; treatment main effect $F_{(1,15)}=$ $1.87, p=0.19, \eta_{\mathrm{P}}^{2}=0.11$ ).
Experiment 3: systemic CB1R antagonism during memory reconsolidation fails to alter drug context-induced cocaine seeking 24 d later

AM251 administration failed to alter responding in the cocainepaired context after a 21 -d drug-free period followed by at least 
two extinction sessions, relative to VEH $(2 \times 2$ ANOVA context main effect only, $F_{(1,15)}=92.46, p<0.0001, \eta_{\mathrm{P}}^{2}=0.86$; treatment $\times$ context interaction, $F_{(1,15)}=0.16, p=0.70, \eta_{\mathrm{P}}^{2}=0.01$; treatment main effect, $F_{(1,15)}=1.14, p=0.30, \eta_{\mathrm{P}}^{2}=0.07$; Fig. $\left.3 C\right)$. Thus, activelever responding in the cocaine-paired context was higher than in the extinction context independent of treatment. Time course analysis of active-lever presses in the cocaine-paired context confirmed that AM251 did not alter responding $(2 \times 6$ ANOVA time main effect only, $F_{(5,75)}=20.08, p<0.0001, \eta_{\mathrm{P}}^{2}=0.57$; treatment $\times$ time interaction, $F_{(5,75)} \leq 0.36, p=0.88, \eta_{\mathrm{P}}^{2}=0.02$; treatment main effect, $F_{(1,15)}=0.57, p=0.46, \eta_{\mathrm{P}}^{2}=0.04$; Fig. $\left.3 D\right)$. Post hoc comparisons indicated that active-lever responding declined after the first 20 -min interval independent of treatment (interval 1>intervals 2-6, Tukey's tests, $p<0.05$ ). Inactive-lever responding remained low in both contexts independent of treatment $(2 \times 2$ ANOVA treatment $\times$ context interaction, $F_{(1,15)}=0.16, p=0.69, \eta_{\mathrm{P}}^{2}=$ 0.01 ; context main effect, $F_{(1,15)}=1.44, p=0.25, \eta_{\mathrm{P}}^{2}=0.09$; treatment main effect, $F_{(1,15)}=0.93, p=0.35, \eta_{\mathrm{P}}^{2}=0.06$; Fig. $3 E$ ). Time course analysis indicated that inactive-lever responding declined across time $\left(2 \times 6\right.$ ANOVA time main effect only, $F_{(5,75)}=13.31$, $p<0.0001, \eta_{\mathrm{P}}^{2}=0.47$, intervals $1>$ intervals $2-6$, Tukey's tests, $p<0.05$; Fig. $3 F$ ) independent of treatment (treatment $\times$ time interaction, $F_{(5,75)}=1.76, p=0.13, \eta_{\mathrm{P}}^{2}=0.10$; treatment main effect $\left.F_{(1,15)}=1.02, p=0.33, \eta_{\mathrm{P}}^{2}=0.06\right)$.

\section{Experiment 4: systemic CB1R antagonism inhibits memory retrieval-induced molecular changes in the BLA during memory reconsolidation}

In brain tissue collected during memory reconsolidation (Fig. $4 A, B, H)$, BLA zif268 expression varied as a function of memory retrieval and AM251 treatment $(2 \times 2$ ANOVA, treatment $\times$ retrieval interaction, $F_{(1,38)}=18.91, p<0.0001, \eta_{\mathrm{P}}^{2}=0.33$; treatment main effect, $F_{(1,38)}=9.08, p=0.005, \eta_{\mathrm{P}}^{2}=0.19$; retrieval main effect, $F_{(1,38)}=9.16, p=0.004, \eta_{\mathrm{P}}^{2}=0.19$; Fig. $\left.4 C\right)$. Post hoc comparisons indicated that memory retrieval increased zif268 expression relative to no-memory retrieval (i.e., home-cage stay; Sidak's tests, $p<0.05$ ). Furthermore, systemic AM251 administration after memory retrieval reduced zif268 expression relative to VEH (Sidak's test, $p<0.05$ ), such that zif268 expression no longer differed from those in the no-memory retrieval controls. Similar to zif268, BLA Arc expression varied as a function of memory retrieval and AM251 treatment $(2 \times 2$ ANOVA, treatment $\times$ retrieval interaction, $F_{(1,38)}=5.61, p=0.02, \eta_{\mathrm{P}}^{2}=0.13$; treatment main effect, $F_{(1,38)}=0.53, p=0.47, \eta_{\mathrm{P}}^{2}=0.01$; retrieval main effect, $F_{(1,38)}=13.03, p=0.0009, \eta_{\mathrm{P}}^{2}=0.26$; Fig. $\left.4 D\right)$. Post hoc comparisons indicated that memory retrieval increased Arc expression relative to no-memory retrieval (Sidak's tests, $p=0.06$ ). Furthermore, systemic AM251 administration after memory retrieval modestly attenuated Arc expression during memory reconsolidation relative to VEH (Sidak's test, $p=0.06$ ), such that Arc expression no longer differed from those in the no-memory retrieval controls.

Similar to IEG expression, glutamate receptor subunit phosphorylation varied as a function of memory retrieval and AM251 treatment. These results are reported in Figure $4 E-G$. CNX was used as loading control for these assays. Mean optical density values for CNX did not vary as a function of memory retrieval or treatment $(2 \times 2$ ANOVA, treatment $\times$ retrieval interaction, $F_{(1,38)}=3.61, p=0.07, \eta_{\mathrm{P}}^{2}=0.09$; treatment main effect, $F_{(1,38)}=$ $1.17, p=0.29, \eta_{\mathrm{P}}^{2}=0.03$; retrieval main effect, $F_{(1,38)}=0.19$, $p=0.67, \eta_{\mathrm{P}}^{2}=0.005$; Fig. $4 I$ ).

Src-mediated phosphorylation of NMDAR GluN2B ${ }^{\mathrm{Y} 1472}$ (pGluN2B) facilitates proper GluN2B synaptic localization, learning, and amygdalar synaptic plasticity (Nakazawa et al., 2006).
BLA pGluN2B levels varied as a function of memory retrieval and treatment $(2 \times 2$ ANOVA, treatment $\times$ retrieval interaction, $F_{(1,38)}=20.74, p<0.0001, \eta_{\mathrm{P}}^{2}=0.35$; treatment main effect, $F_{(1,38)}=1.43, p=0.24, \eta_{\mathrm{P}}^{2}=0.03$; retrieval main effect, $F_{(1,38)}=$ 5.60, $p=0.02, \eta_{\mathrm{P}}^{2}=0.12$; Fig. $4 E$ ). Post hoc comparisons indicated that memory retrieval increased pGluN2B relative to no-memory retrieval (Sidak's tests, $p<0.05$ ). Moreover, systemic AM251 administration after memory retrieval reduced pGluN2B during memory reconsolidation relative to VEH (Sidak's test, $p<0.05$ ), such that pGluN2B levels no longer differed from those in the no-memory retrieval controls. Notably, a trend for a retrieval-dependent AM251-induced increase in total GluN2B levels could have enhanced this effect by increasing the denominator $(2 \times 2$ ANOVA, treatment $\times$ retrieval interaction, $F_{(1,38)}=3.74, p=0.06, \eta_{\mathrm{P}}^{2}=0.09$; treatment main effect, $F_{(1,38)}=8.40, p=0.006, \eta_{\mathrm{P}}^{2}=0.18$; retrieval main effect, $F_{(1,38)}=0.23, p=0.63, \eta_{\mathrm{P}}^{2}=0.006$; Fig. $\left.4 J\right)$.

PKA-mediated phosphorylation of AMPAR GluA1 ${ }^{\mathrm{S} 845}$ (pGluA1) promotes GluA1 trafficking to the postsynaptic density and fear-memory destabilization after memory retrieval (Clem and Huganir, 2010). BLA pGluA1 levels varied as a function of memory retrieval and AM251 treatment $(2 \times 2$ ANOVA, treatment $\times$ retrieval interaction, $F_{(1,38)}=8.04, p=0.007, \eta_{\mathrm{P}}^{2}=0.17$; retrieval main effect, $F_{(1,38)}=7.15, p=0.01, \eta_{\mathrm{P}}^{2}=0.16$; treatment main effect, $F_{(1,38)}=1.70, p=0.20, \eta_{\mathrm{P}}^{2}=0.04$; Fig. $\left.4 F\right)$ with no change in total GluA1 levels $(2 \times 2$ ANOVA, treatment $\times$ retrieval interaction, $F_{(1,38)}=1.83, p=0.007, \eta_{\mathrm{P}}^{2}=0.05$; treatment main effect, $F_{(1,38)}=0.11, p=0.74, \eta_{\mathrm{P}}^{2}=0.003$; retrieval main effect, $F_{(1,38)}=0.38, p=0.54, \eta_{\mathrm{P}}^{2}=0.01$; Fig. $\left.4 K\right)$. Post hoc comparisons indicated that memory retrieval increased pGluA1 relative to no-memory retrieval (Sidak's test, $p<0.05$ ). Moreover, systemic AM251 administration after memory retrieval reduced pGluA1 during memory reconsolidation relative to VEH (Sidak's test, $p<0.05$ ), such that pGluA1 levels no longer differed from those in no-memory retrieval controls.

Src-mediated phosphorylation of AMPAR GluA2 ${ }^{\mathrm{Y} 876}$ (pGluA2) disrupts GluA2 association with postsynaptic density scaffolding proteins, thereby reducing GluA2 synaptic expression (Hayashi and Huganir, 2004). Memory retrieval reduced BLA pGluA2 during memory reconsolidation relative to no-memory retrieval independent of treatment $\left(2 \times 2\right.$ ANOVA, retrieval main effect only, $F_{(1,38)}=$ $6.78, p=0.01, \eta_{\mathrm{P}}^{2}=0.15$; treatment $\times$ retrieval interaction, $F_{(1,38)}=$ 6.78, $p=0.01, \eta_{\mathrm{P}}^{2}=0.01$; treatment main effect, $F_{(1,38)}=6.78$, $p=0.01, \eta_{\mathrm{P}}^{2}=0.02$; Fig. $4 G$ ), without altering total GluA2 levels $\left(2 \times 2\right.$ ANOVA, treatment $\times$ retrieval interaction, $F_{(1,38)}=1.59$, $p=0.21, \eta_{\mathrm{P}}^{2}=0.04$; treatment main effect, $F_{(1,38)}=0.32, p=0.26$, $\eta_{\mathrm{P}}^{2}=0.03$; retrieval main effect, $F_{(1,38)}=0.12, p=0.73, \eta_{\mathrm{P}}^{2}=0.003$; Fig. 4L). Thus, AM251 failed to alter pGluA2 or total GluA2 levels.

\section{Experiments 1-3: systemic CB1R antagonism during} memory reconsolidation inhibits molecular changes in the BLA during reinstatement $3 \mathrm{~d}$, but not $24 \mathrm{~d}$, posttreatment To capture potential protracted effects of AM251 on protein expression during the reinstatement test, BLA tissue was collected immediately after the 2 -h test session in the cocaine-paired context in experiments $1-3$ (Fig. 5A). In experiment 1 (Fig. 5B), systemic AM251 administration immediately after memory retrieval (i.e., during memory reconsolidation) significantly reduced BLA zif268 $\left(t_{(13)}=2.94, p=0.01, g=1.52\right.$; Fig. $\left.5 C\right)$, total GluN2B $\left(t_{(13)}=3.48\right.$, $p=0.004, g=1.80$; Fig. $5 E)$, and total GluA1 $\left(t_{(13)}=4.41, p=0.001\right.$, $g=2.13$; Fig. $5 F$ ) expression relative to $\mathrm{VEH} 3 \mathrm{~d}$ posttreatment. AM251 administration also increased Arc expression $\left(t_{(13)}=4.61\right.$, $p=0.0005, g=2.39$; Fig. 5D) and failed to alter total GluA2 levels 

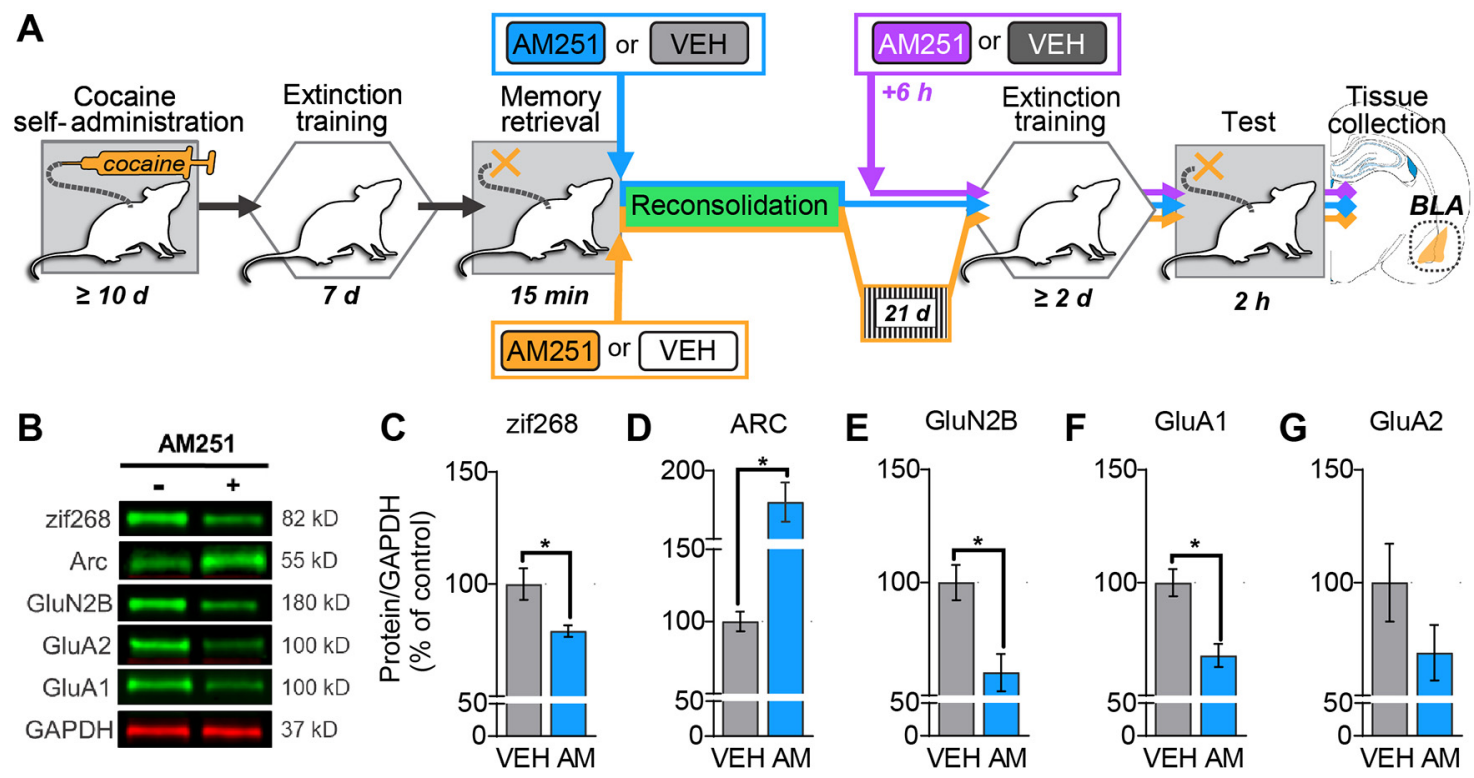

G GluA2
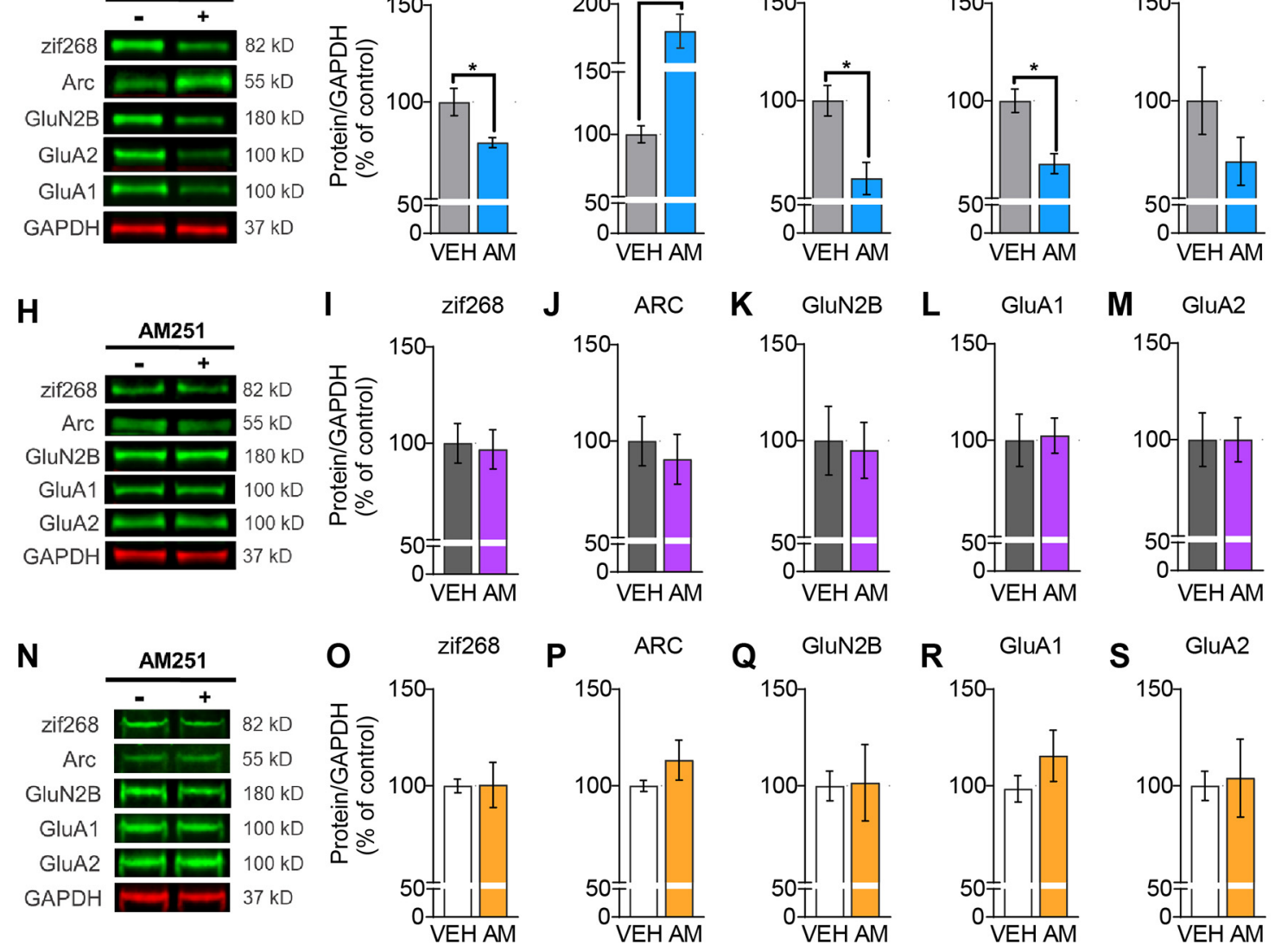

Figure 5. Systemic AM251 administration after memory retrieval elicits time-dependent changes in BLA IEG and total glutamate receptor subunit expression levels at test. A, Experimental timeline. Systemic AM251 (AM; $3 \mathrm{mg} / \mathrm{kg}$, i.p.) or VEH was administered immediately or $6 \mathrm{~h}$ after cocaine-memory retrieval. Cocaine-seeking behavior was assessed in the cocaine-paired context three or $24 \mathrm{~d}$ later, after at least two extinction sessions in experiments $1-3$. BLA tissue samples were collected 1-2 min after the test session. $\boldsymbol{B}, \boldsymbol{H}, \boldsymbol{N}$, Composite images of representative Western blottings for experiments 1-3, respectively. C $-\mathbf{G}$, Effects of systemic AM251 administration immediately after memory retrieval on total protein levels (mean \pm SEM) in the BLA at test, $3 \mathrm{~d}$ later in experiment 1. I-M, Effects of systemic AM251 administration $6 \mathrm{~h}$ after memory retrieval on total protein levels (mean \pm SEM) in the BLA at test, $3 \mathrm{~d}$ later in experiment 2. $\mathbf{0}-\mathbf{S}$, Effects of systemic AM251 administration immediately after memory retrieval on total protein levels (mean \pm SEM) in the BLA at test, $24 \mathrm{~d}$ later in experiment 3 . Values were normalized to the loading control, GAPDH, and expressed as a percentage of the VEH-treated group. Symbols: $* t$ test, $p<0.05$; \#Pearson's $r$ correlation coefficient, $p<0.05$ ( $n=7-9$ per group).

$\left(t_{(13)}=1.63, p=0.125, g=1.17\right.$; Fig. $\left.5 G\right)$ relative to $\mathrm{VEH}$ at the same time point. In experiment 2 (Fig. $5 H$ ), systemic AM251 administration $6 \mathrm{~h}$ after memory retrieval (i.e., outside the memory reconsolidation window) failed to alter BLA zif268 $\left(t_{(15)}=\right.$ $0.08, p=0.94, g=0.04$; Fig. $5 I)$, Arc $\left(t_{(15)}=0.29, p=0.77, g=0.14\right.$; Fig. 5J), GluN2B $\left(t_{(15)}=0.22, p=0.83, g=0.11\right.$; Fig. $\left.5 K\right)$, GluA1 $\left(t_{(15)}=0.12, p=0.91, g=0.07\right.$; Fig. $\left.5 L\right)$, or GluA2 levels $\left(t_{(15)}=0.008\right.$, $p=0.99, g=0.004$; Fig. $5 M$ ) relative to $\mathrm{VEH}$ at test, $3 \mathrm{~d}$ posttreatment. In experiment 3 (Fig. $5 \mathrm{~N}$ ), systemic AM251 administration immediately after memory retrieval did not alter zif268 $\left(t_{(15)}=0.04\right.$, $p=0.97, g=0.02$; Fig. 50$)$, Arc $\left(t_{(15)}=1.18, p=0.26, g=0.57\right.$; Fig. $5 P)$, GluN2B $\left(t_{(15)}=0.07, p=0.94, g=0.03\right.$; Fig. 5Q), GluA1 $\left(t_{(15)}=\right.$ $1.10, p=0.29, g=0.53$; Fig. $5 R)$, or GluA2 levels $\left(t_{(15)}=0.18\right.$, $p=0.85, g=0.09$; Fig. $5 S$ ) relative to $\mathrm{VEH}$ at test, $24 \mathrm{~d}$ later.
Experiment 5: systemic CB1R antagonism after memory retrieval increases sEPSC frequency in BLA PNs

To determine whether AM251-induced memory reconsolidation impairments and associated molecular changes were paralleled by changes in synaptic transmission in the BLA, whole-cell patchclamp recordings were obtained from BLA PNs. Slices were prepared on average $30 \mathrm{~min}$ after memory retrieval or no-memory retrieval and systemic AM251 or VEH treatment (Fig. 6A) to detect possible retrieval-associated transient changes in AMPAR rectification (Hong et al., 2013; Rao-Ruiz et al., 2015). Recording electrodes were targeted at visually identified PNs, and definitive spiny pyramidal cell morphology was confirmed by fluorescence imaging of Alexa Fluor 568 included in the patch pipette. Voltageclamped $\left(\mathrm{V}_{\mathrm{h}}=-60 \mathrm{mV}\right)$ PNs exhibited sEPSCs, and electrical 
A

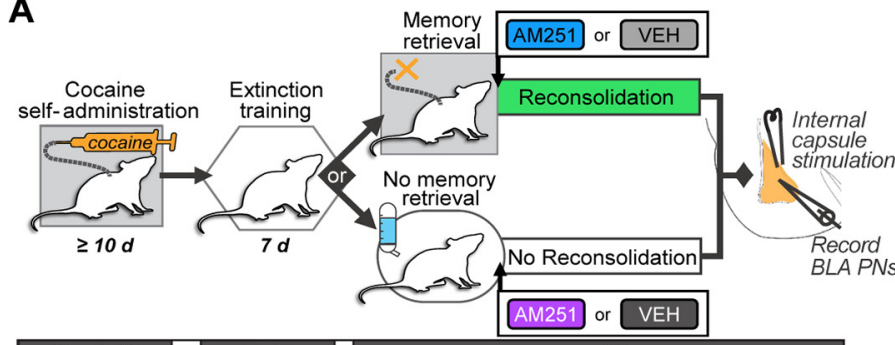

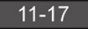

C
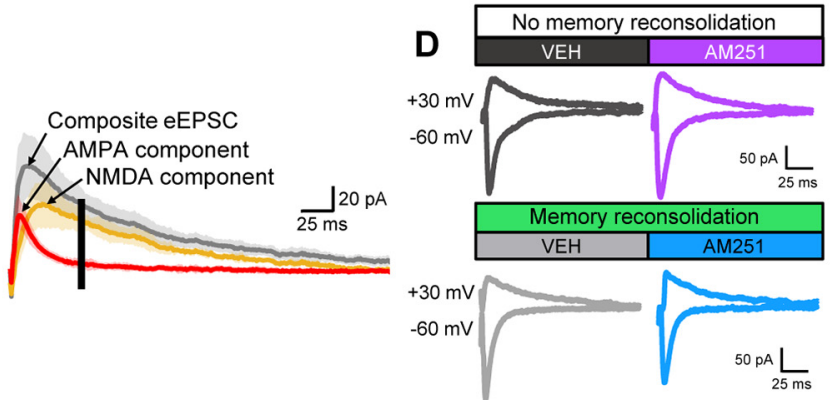

B

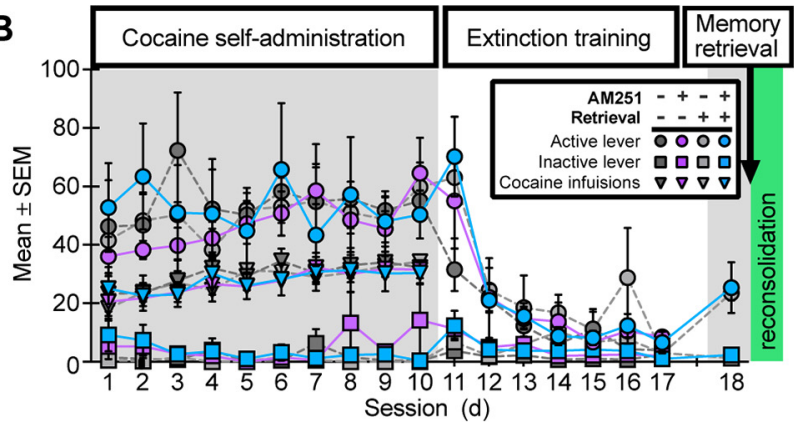

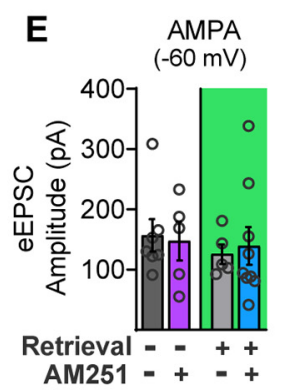
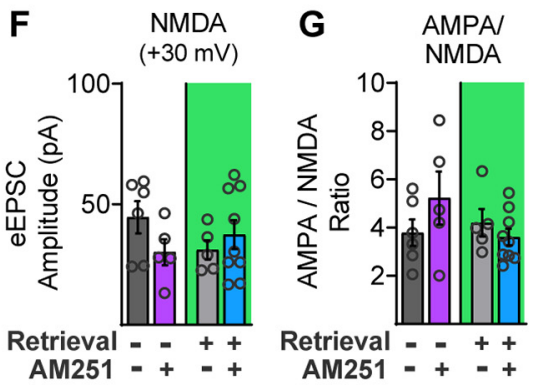

H
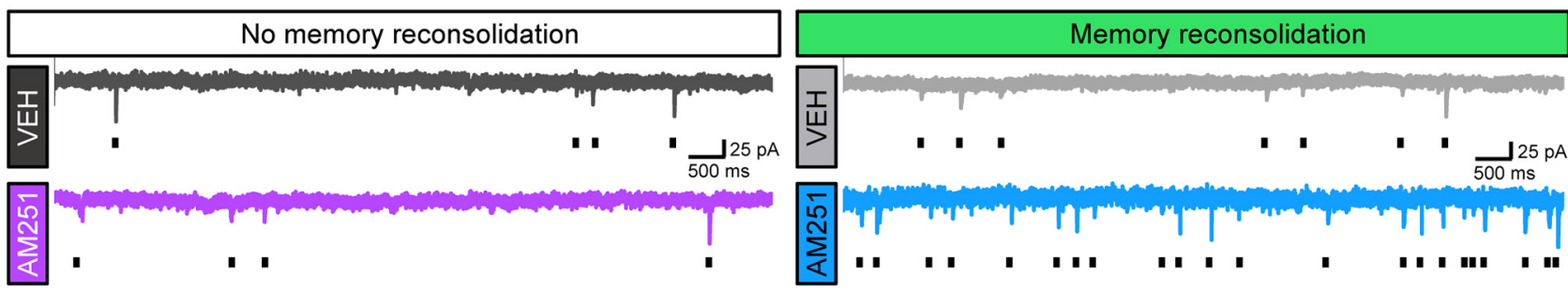

I

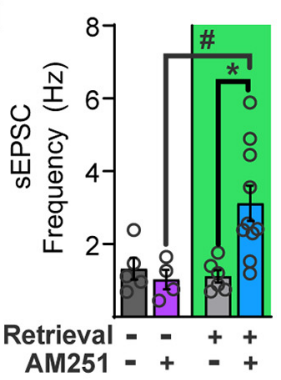

$\mathbf{J}$

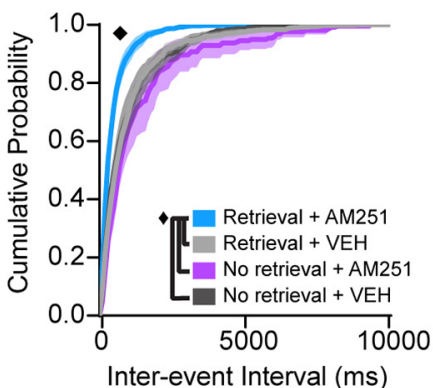

K

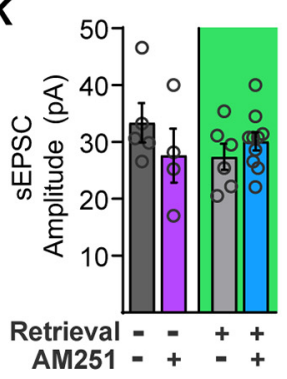

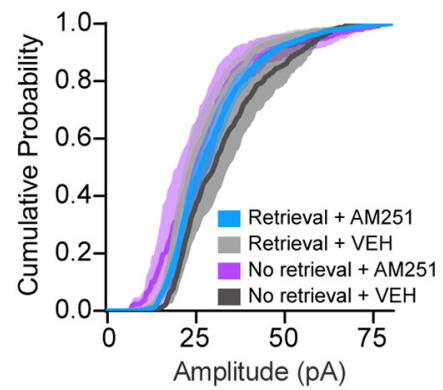

Figure 6. Systemic AM251 administration after memory retrieval increases sEPSC frequency in BLA PNs during cocaine-memory reconsolidation. A, Experimental timeline. AM251 (3 mg/kg, i.p.) or VEH was administered immediately after cocaine-memory retrieval or no-memory retrieval [for behavioral history, see Extended Data Fig. 6-1; $n$ biological (technical replicate) $=4$ (4) to 5 (9) per group]. Brain slices were prepared for whole-cell recording within an average of 30 min after treatment. Schematic depicts stimulating electrode placement in the internal capsule and recording electrode placement in the basal nucleus. $\boldsymbol{B}$, Lever responses and cocaine infusions during drug self-administration, extinction training, and the 15 -min memory retrieval session. C, eEPSCs (mean across all cells recorded \pm SEM) recorded at $+30 \mathrm{mV}$ in aCSF (gray) or AP5 (leaving the isolated AMPAR component; red), and superimposed digital subtraction (to visualize digitally-derived NMDAR component; orange). NMDAR-mediated eEPSC amplitudes were measured $50 \mathrm{~ms}$ after stimulus onset to eliminate AMPAR component contribution (black bar). $\boldsymbol{D}$, Representative recordings of eEPSC obtained from BLA PN cells in aCSF, in each group at -60 and $+30 \mathrm{mV}$ holding potentials. Peak amplitude of AMPA (mean \pm SEM, at $-60 \mathrm{mV} ; \boldsymbol{E}$ ) and NMDA (mean \pm SEM, at $+30 \mathrm{mV} ; \boldsymbol{F}$ ) components in aCSF. G, AMPA/NMDA ratio (mean \pm SEM). $\boldsymbol{H}$, Representative sEPSC recordings with ticks indicating individual events. sEPSC frequency (mean \pm SEM; $I$ ) and the cumulative probability distribution of sEPSC interevent intervals (mean \pm SEM; $\boldsymbol{J}$ ). SEPSC amplitude (mean \pm SEM; $\boldsymbol{K}$ ) and the cumulative probability distribution of sEPSC amplitudes (mean \pm SEM; $\boldsymbol{L}$ ). Symbols: ANOVA, \#retrieval simple main effect, Sidak's test, $p<0.05 ; *$ treatment simple main effect, Sidak's test, $p<0.05$; Kruskal-Wallis test, $p<0.05$, Dunn's test, $p<0.05$.

stimulation of the IC typically elicited eEPSCs. Cells that did not respond to IC stimulation, including PNs, were not experimented on. Data from two cells were excluded from analysis because their sEPSC frequencies were greater than two standard deviations from the group mean. Data points overlaid on bar graphs represent the magnitude of the measured parameter of individual cells obtained between $\sim 10 \mathrm{~min}$ postsectioning and up to $4 \mathrm{~h}$ postmemory retrieval and AM251 or VEH treatment. Notably, there was no correlation between time from memory retrieval/treatment and AMPA/NMDA ratio $\left(r_{(25)}=0.003, p=0.99\right)$ or the rectification index $\left(r_{(45)}=-0.03, p=0.82\right)$ suggesting that synaptic properties did not change over time within the recording time window.

Application of the NMDAR antagonist, APV $(50 \mu \mathrm{M})$, was used to pharmacologically isolate the AMPAR component, and subsequent digital subtraction revealed the NMDA component, of the composite eEPSC (Fig. 6C). Based on the temporal profile of the respective components, the AMPAR and NMDAR components were operationalized as the peak amplitude and the amplitude at $50 \mathrm{~ms}$ of the composite response, respectively. Neither 
Table 2. Outward current frequency and amplitude

\begin{tabular}{|c|c|c|c|c|c|c|c|c|c|c|c|c|c|c|c|c|}
\hline \multirow[b]{2}{*}{ Measure } & \multicolumn{5}{|c|}{ Treatment effects } & \multicolumn{5}{|c|}{ Retrieval effects } & \multicolumn{5}{|c|}{ Treatment $\times$ retrieval effects } & \multirow{2}{*}{$\begin{array}{l}\text { Post hoc effects } \\
\text { Sidak's or Dunn's test }\end{array}$} \\
\hline & Test & df & Statistic & $p$ & $\eta_{\mathrm{P}}^{2}$ & Test & df & Statistic & $p$ & $\eta_{\mathrm{P}}^{2}$ & Test & df & Statistic & $p$ & $\eta_{\mathrm{P}}^{2}$ & \\
\hline \multicolumn{17}{|l|}{$\mathrm{aCSF}(+30 \mathrm{mV})$} \\
\hline Frequency distribution & & & & & & & & & & & $F$ & 3 & 262.70 & $<0.0001$ & 0.30 & Memory retrieval $+\mathrm{AM} 251>$ all other \\
\hline sEPSC amplitude & $F$ & 1,23 & 0.02 & 0.88 & 0.00 & $F$ & 1,23 & 0.19 & 0.66 & 0.01 & $F$ & 1,23 & 1.74 & 0.20 & 0.07 & NA \\
\hline Amplitude distribution & & & & & & & & & & & $F$ & 3 & 17.03 & 0.00 & 0.43 & No retrieval $+\mathrm{AM} 251<$ all other \\
\hline Frequency distribution & & & & & & & & & & & $F$ & 3 & 180.70 & $<0.0001$ & 0.22 & Memory retrieval $+\mathrm{AM} 251>$ all other \\
\hline sEPSC amplitude & $F$ & 1,50 & 0.46 & 0.50 & 0.01 & $F$ & 1,50 & 0.42 & 0.52 & 0.01 & $F$ & 1,50 & 2.09 & 0.16 & 0.04 & NA \\
\hline Amplitude distribution & & & & & & & & & & & $F$ & 3 & 0.36 & 0.95 & 0.00 & NA \\
\hline
\end{tabular}

Effects of treatment (AM251, VEH) and memory retrieval (retrieval, no-retrieval) on mean sEPSC frequency, cumulative frequency distribution, mean peak amplitude, and cumulative amplitude distribution recorded in aCSF alone or in the presence of the NMDAR antagonist, AP5, at $+30 \mathrm{mV}$ in experiment 5. Data shown are ANOVA or non-parametric Kruskal-Wallis effects, effect sizes, and the results of post hoc comparisons.

memory retrieval nor AM251 altered the AMPAR-mediated eEPSC amplitude $(2 \times 2$ ANOVA, treatment $\times$ retrieval interaction, $F_{(1,22)}=0.135, p=0.72, \eta_{\mathrm{P}}^{2}=0.006$; treatment main effect, $F_{(1,22)}=0.006, p=0.94, \eta_{\mathrm{P}}^{2}=0.0003$; retrieval main effect, $F_{(1,22)}=0.40, p=0.53, \eta_{\mathrm{P}}^{2}=0.02$; Fig. $\left.6 D, E\right)$, NMDAR-mediated eEPSC amplitude $(2 \times 2$ ANOVA, treatment $\times$ retrieval interaction, $F_{(1,21)}=2.78, p=0.11, \eta_{\mathrm{P}}^{2}=0.12$; treatment main effect, $F_{(1,21)}=0.25, p=0.62, \eta_{\mathrm{P}}^{2}=0.01$; retrieval main effect, $F_{(1,21)}=$ $0.42, p=0.52, \eta_{\mathrm{P}}^{2}=0.02$; Fig. $\left.6 D, F\right)$, or the AMPA/NMDA eEPSC amplitude ratio $(2 \times 2$ ANOVA, treatment $\times$ retrieval interaction, $F_{(1,21)}=2.63, p=0.12, \eta_{\mathrm{P}}^{2}=0.11$; treatment main effect, $F_{(1,21)}=0.46, p=0.51, \eta_{\mathrm{P}}^{2}=0.02$; retrieval main effect, $F_{(1,21)}=0.93, p=0.35, \eta_{\mathrm{P}}^{2}=0.04$; Fig. $\left.6 G\right)$.

In contrast to the lack of effects on eEPSCs, the sEPSC frequency varied as a function of memory retrieval and systemic AM251 treatment $(2 \times 2$ ANOVA, treatment $\times$ retrieval interaction, $F_{(1,21)}=6.31, p=0.02, \eta_{\mathrm{P}}^{2}=0.23$; treatment main effect, $F_{(1,21)}=3.49, p=0.076, \eta_{\mathrm{P}}^{2}=0.14$; retrieval main effect, $F_{(1,21)}=$ $4.23, p=0.052, \eta_{\mathrm{P}}^{2}=0.17$; Fig. 6 H,J; Table 2). Post hoc comparisons indicated that memory retrieval followed by VEH did not alter the mean sEPSC frequency relative to no-memory retrieval. However, AM251 administration after memory retrieval, but not after no-memory retrieval, increased the mean sEPSC frequency relative to VEH (Sidak's test, $p<0.05$; Fig. $6 I$ ) and produced a leftward shift in the cumulative probability distribution of sEPSC interevent intervals relative to $\mathrm{VEH}$ after memory retrieval or AM251 after no-memory retrieval (Kruskal-Wallis test, $H_{(3)}=$ 68.64, $p<0.0001, \eta_{\mathrm{P}}^{2}=0.148$, Dunn's test, $p<0.05$; Fig. $\left.6 J\right)$. Neither memory retrieval nor AM251 altered the mean sEPSC amplitude $(2 \times 2$ ANOVA, treatment $\times$ retrieval interaction, $F_{(1,21)}=2.36, p=0.14, \eta_{\mathrm{P}}^{2}=0.10$; treatment main effect, $F_{(1,21)}=$ $0.30, p=0.59, \eta_{\mathrm{P}}^{2}=0.01$; retrieval main effect, $F_{(1,21)}=0.41$, $p=0.53, \eta_{\mathrm{P}}^{2}=0.02$; Fig. $6 \mathrm{~K}$ ) or the cumulative probability distribution of sEPSC amplitudes (Kruskal-Wallis test, $H_{(3)}=4.51$, $p=0.21, \eta_{\mathrm{P}}^{2}=0.007$; Fig. $6 L$ )

To verify our measurements of non-pharmacologically isolated AMPAR EPSCs and determine AMPAR rectification indexes, we repeated our measurements on pharmacologically isolated AMPAR eEPSCs and sEPSCs (Fig. 7A). In the presence of the NMDAR antagonist, AP5 $(50 \mu \mathrm{M})$, neither memory retrieval nor systemic AM251 administration altered synaptic responses to IC stimulation, including peak AMPAR eEPSC amplitude at $-60 \mathrm{mV}(2 \times 2$ ANOVA, treatment $\times$ retrieval interaction $F_{(1,41)}=0.0005, p=0.98, \eta_{\mathrm{P}}^{2}=0.00,001$; treatment main effect, $F_{(1,41)}=2.47, p=0.12, \eta_{\mathrm{P}}^{2}=0.06$; retrieval main effect, $F_{(1,41)}=0.70, p=0.41, \eta_{\mathrm{P}}^{2}=0.02$; Fig. $\left.7 B\right)$ and $+30 \mathrm{mV}(2 \times 2$ ANOVA, treatment $\times$ retrieval interaction $F_{(1,41)}=1.04$, $p=0.32, \eta_{\mathrm{P}}^{2}=0.02$; treatment main effect, $F_{(1,41)}=0.38, p=0.54$, $\eta_{\mathrm{P}}^{2}=0.009$; retrieval main effect, $F_{(1,41)}=0.19, p=0.67, \eta_{\mathrm{P}}^{2}=$ 0.005; Fig. $7 C)$, or the AMPAR eEPSC rectification index $(2 \times 2$ ANOVA, treatment $\times$ retrieval interaction $F_{(1,40)}=0.003$, $p=0.95, \eta_{\mathrm{P}}^{2}=0.00,007$; treatment main effect, $F_{(1,40)}=0.0 .07$, $p=0.78, \eta_{\mathrm{P}}^{2}=0.002$; retrieval main effect, $F_{(1,40)}=0.05, p=0.83$, $\eta_{\mathrm{P}}^{2}=0.001$; Fig. 7D).

In the presence of AP5, the mean AMPAR sEPSC frequency varied as a function of memory retrieval and AM251 treatment $\left(2 \times 2\right.$ ANOVA, retrieval $\times$ treatment interaction, $F_{(1,46)}=6.24$, $p=0.02, \eta_{\mathrm{P}}^{2}=0.12$; retrieval main effect, $F_{(1,46)}=6.72, p=0.02$, $\eta_{\mathrm{P}}^{2}=0.13$; treatment main effect, $F_{(1,46)}=1.82, p=0.18, \eta_{\mathrm{P}}^{2}=$ 0.04; Fig. 7E,G). Post hoc comparisons indicated that memory retrieval followed by VEH did not alter mean sEPSC frequency relative to no-memory retrieval. However, systemic AM251 administration after memory retrieval, but not after no-memory retrieval, increased sEPSC frequency relative to VEH (Sidak's test, $p<0.05$; Fig. $7 F$ ) and produced a leftward shift in the cumulative probability distribution of sEPSC interevent intervals relative to VEH after memory retrieval or AM251 after no-memory retrieval (Kruskal-Wallis test, $H_{(3)}=41.72, p<0.0001, \eta_{\mathrm{P}}^{2}=$ 0.10 ; Dunn's test, $p<0.05$; Fig. $7 G)$. Neither memory retrieval nor AM251 treatment altered the mean amplitude of sEPSCs $\left(2 \times 2\right.$ ANOVA, treatment $\times$ retrieval interaction $F_{(1,46)}=0.63$, $p=0.43, \eta_{\mathrm{P}}^{2}=0.01$; treatment main effect, $F_{(1,46)}=1.22, p=0.28$, $\eta_{\mathrm{P}}^{2}=0.03$; retrieval main effect, $F_{(1,46)}=0.43, p=0.52, \eta_{\mathrm{P}}^{2}=$ 0.009 ; Fig. $7 H$ ) or the cumulative probability distribution of sEPSC amplitudes (Kruskal-Wallis test, $H_{(3)}=0.40, p=0.94$, $\eta_{\mathrm{P}}^{2}=0.0003$; Fig. $\left.7 I\right)$.

\section{Discussion}

The main finding of this study is that CB1R signaling critically modulates memory reconsolidation processes necessary for subsequent drug context-induced cocaine-seeking behavior in an instrumental model of drug relapse. Furthermore, memory retrieval induces CB1R-dependent changes in IEG expression, glutamate receptor subunit phosphorylation, and excitatory synaptic transmission in the BLA during memory reconsolidation.

Systemic CB1R antagonism during cocaine-memory reconsolidation (i.e., immediately after memory retrieval) reduced drug context-induced cocaine-seeking behavior $3 \mathrm{~d}$ later, relative to VEH (Fig. 1). The CB1R antagonist, AM251 does not alter inhibitory avoidance (Gobira et al., 2013) or grooming behaviors (Hodge et al., 2008) at similar doses, suggesting it is not aversive. Furthermore, AM251 alone did not alter the expression of drugseeking behavior despite its long half-life (i.e., $22 \mathrm{~h}$; McLaughlin 
A
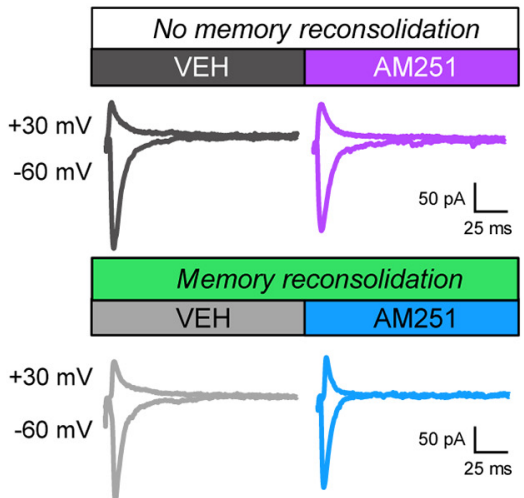

B

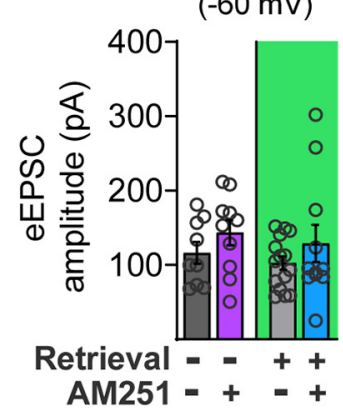

C

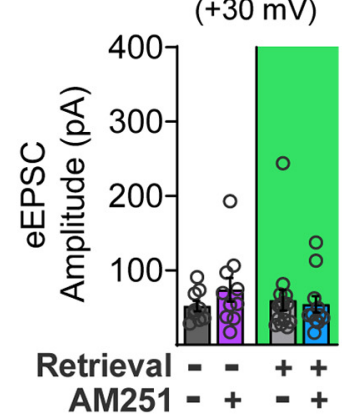

D
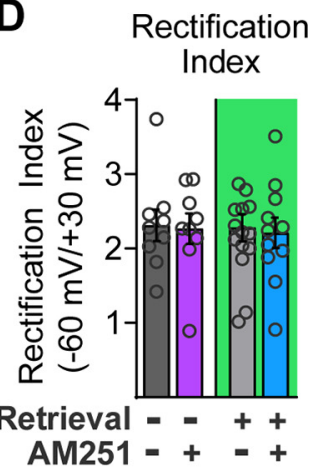

E

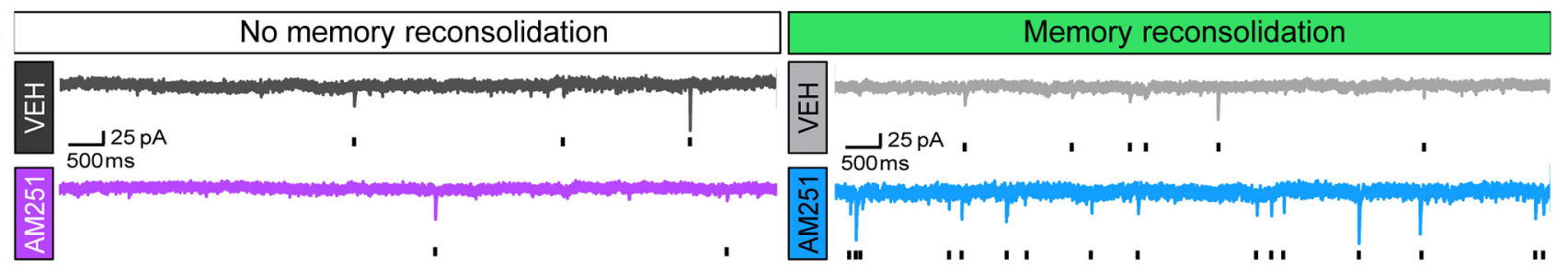

F

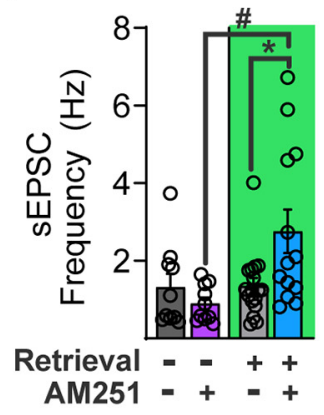

G

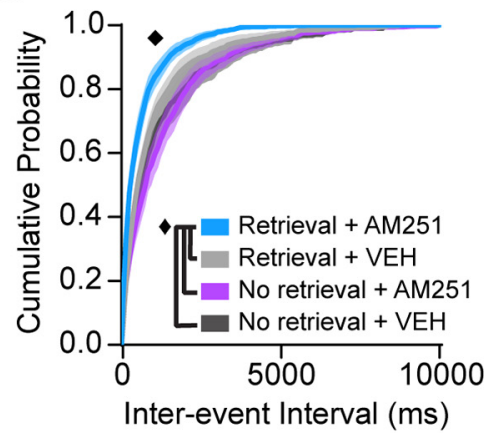

H

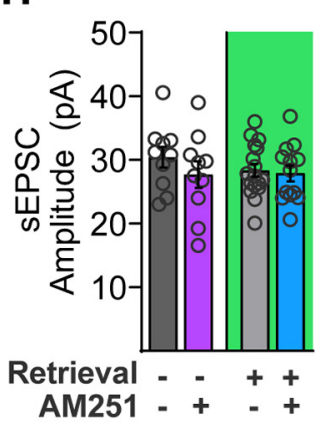

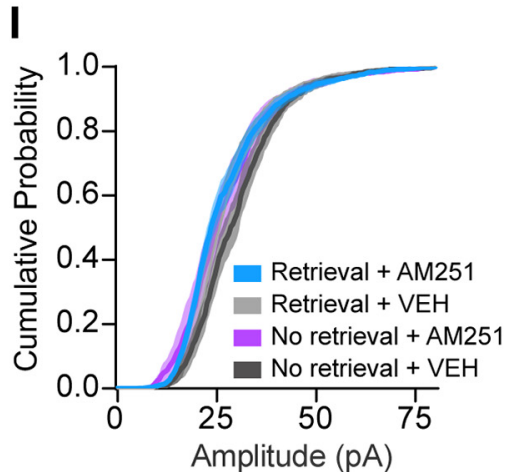

Figure 7. Systemic AM251 administration after memory retrieval increases AMPAR-mediated sEPSC frequency in BLA PNs during cocaine-memory reconsolidation. $\boldsymbol{A}$, Representative eEPSCS recordings in the presence of the NMDAR antagonist, AP5, at +30 and $-60 \mathrm{mV}$. Peak AMPAR-mediated eEPSC amplitudes [mean \pm SEM; $n$ biological (technical replicate) $=5$ (9-15) per group] at $-60 \mathrm{mV}(\boldsymbol{B})$ and $+30 \mathrm{mV}(\boldsymbol{C})$. D, Rectification index calculated as the ratio of the peak eEPSC amplitude at -60 and $+30 \mathrm{mV}$ in the presence of AP5. $\boldsymbol{E}$, Representative sEPSC recordings with ticks indicating individual events. $\boldsymbol{F}$, sEPSC frequency (mean \pm SEM). $\boldsymbol{G}$, Cumulative probability distribution of $s$ EPSC interevent intervals (mean \pm SEM). sEPSC amplitude (mean $\pm \mathrm{SEM} ; \boldsymbol{H}$ ) and cumulative probability distribution of amplitudes (mean $\pm \mathrm{SEM}$; $\boldsymbol{I}$ ). Symbols: ANOVA, \#retrieval simple main effect, Sidak's test, $p<0.05 ; * A N O V A$, treatment simple main effect, Sidak's test, $p<0.05 ; \diamond$ Kruskal-Wallis test, $p<0.05$, Dunn's test, $p<0.05$.

et al., 2003; Fig. 2). These observations suggest that CB1R signaling is necessary for cocaine-memory reconsolidation in an instrumental model of drug relapse, thereby expanding on the known involvement of CB1Rs in Pavlovian morphine, nicotine, and methamphetamine memory reconsolidation (Yu et al., 2009; Fang et al., 2011; De Carvalho et al., 2014). CB1R signaling is not required for social reward memory reconsolidation (Achterberg et al., 2014); as such, selective effects of CB1R antagonism on memory reconsolidation across drug classes and paradigms are especially encouraging from a substance use disorder treatment perspective.

Systemic CB1R antagonism inhibited molecular adaptations in the BLA during memory reconsolidation and cocaine-seeking behavior $3 \mathrm{~d}$ later at test. Specifically, cocaine-memory retrieval augmented zif268 and Arc expression during reconsolidation, and this effect was blocked by AM251 (Fig. 4). CB1R-dependent IEG expression in the BLA is probably required for memory re-stabilization given that intra-BLA zif268 or Arc antisense administration disrupts cocaine-CPP and cue-cocaine memory reconsolidation in other paradigms (Lee et al., 2005, 2006; Théberge et al., 2010; Alaghband et al., 2014). AM251 administration during reconsolidation also reduced BLA zif268 expression $3 \mathrm{~d}$ later at test (Fig. $5 C$ ). Reinstatement of cocaineseeking behavior is associated with increased zif268 mRNA expression (Hearing et al., 2010), suggesting that zif268 expression tracks motivation for cocaine. Importantly, memory retrieval-dependent AM251 effects on zif268 expression may indicate diminished motivation for cocaine at test because of CB1R antagonist-induced affective-memory impairment initiated during reconsolidation.

Interestingly, cocaine-memory retrieval triggered CB1R-dependent increases in pGluN2 $\mathrm{B}^{\mathrm{Y} 1472}$ and $\mathrm{pGluA} 1^{\mathrm{S} 845}$, consistent with enhanced GluN2B synaptic stability (Nakazawa et al., 2006) and GluA1 synaptic recruitment (Hong et al., 2013), respectively, as well as CB1R-independent decreases in pGluA2 ${ }^{\mathrm{Y} 876}$ (Fig. 5). Previous research has indicated the necessity of PKA activation (Arguello et al., 2014) and the importance of NMDARdependent CI-AMPAR (GluA2-containing) endocytosis followed closely by CP-AMPAR (GluA2-lacking; i.e., GluA1) synaptic trafficking in the amygdala for memory reconsolidation (Clem and Huganir, 2010; Hong et al., 2013; Lopez et al., 2015; Yu et al., 2016). In our study, decreases in 
pGluA2 ${ }^{\mathrm{Y} 876}$, consistent with diminished Src-mediated CIAMPAR endocytosis (Hayashi and Huganir, 2004), likely captured a time point when CI-AMPAR synaptic expression was restored after transient endocytosis, while CP-AMPAR synaptic insertion was still ongoing (Rao-Ruiz et al., 2015). Thus, cocaine-memory reconsolidation may involve CB1R-dependent and NMDAR-dependent CP-AMPAR synaptic insertion and CB1R-independent CI-AMPAR endocytosis in the BLA. For additional insight, future research will need to fully characterize time-dependent changes in plasticity-related proteins, including GluN1, GluN2A, pGluA1 ${ }^{\mathrm{S} 831}$, pGluA2 ${ }^{\mathrm{S} 880}$, within and outside of the BLA.

The robust molecular adaptations observed $45 \mathrm{~min}$ after memory retrieval were paralleled by subtle influences on BLA synaptic physiology observed in slices prepared $\sim 30 \mathrm{~min}$ after memory retrieval and systemic treatment. During reconsolidation, IC stimulation did not reveal changes in AMPA/NMDA ratio, eEPSC peak amplitude, or eEPSC rectification in BLA PNs (Figs. 6, 7). Thus, it is possible that the molecular adaptations observed in BLA whole-cell lysates (Fig. 4) did not affect the receptor composition of IC $\rightarrow$ BLA synapses. Alternatively, the molecular adaptations of cocaine-memory reconsolidation may be similar to fear-memory reconsolidation which involves equalconductance exchange of CI-AMPARs to CP-AMPARs and no change in $\mathrm{IC} \rightarrow \mathrm{BLA}$ synaptic strength, with a transient increase in rectification reported in slices prepared $5 \mathrm{~min}$, but not $1 \mathrm{~h}$, after memory retrieval (Hong et al., 2013; Rao-Ruiz et al., 2015). In this case, the temporal dynamics of IC $\rightarrow$ BLA synaptic plasticity during cocaine-memory and fear-memory reconsolidation may differ, or the timing of our synaptic physiology protocols did not permit the detection of transient changes in rectification. Finally, molecular adaptations in the BLA might reflect changes in receptor trafficking at non$\mathrm{IC} \rightarrow \mathrm{BLA}$ synapses or other cell types (i.e., GABAergic interneurons).

We discovered memory retrieval-dependent increases in sEPSC frequency in BLA PNs (Figs. 6, 7). Importantly, memory retrieval-dependent sEPSC frequency increases were only observed when CB1Rs were blocked systemically. This suggests that potential cocaine-memory retrieval-associated plasticity occurs at non-IC excitatory inputs to BLA PNs (e.g., sensory cortices, prefrontal cortex, or ventral hippocampus; Sah et al., 2003; LeDoux, 2007). Systemic CB1R antagonism enables potentiation at these inputs and may create "synaptic noise" that impedes plasticity associated with memory reconsolidation. Thus, CB1R signaling may facilitate memory reconsolidation by reducing synaptic noise.

Collectively, cocaine-memory reconsolidation primarily involves plasticity at BLA PN synapses in the form of a memory retrieval-induced increase in excitability or vesicle release probability of glutamatergic afferents that is inhibited by CB1R signaling. This implies that $\mathrm{CB} 1 \mathrm{R}$ signaling is necessary to reduce glutamatergic synaptic excitation of BLA PNs during memory reconsolidation. Initially, this appears to be contradictory to the effects of CB1R antagonism on memory reconsolidation in the present study and to the known role of glutamate in memory reconsolidation (Milton et al., 2008; Rao-Ruiz et al., 2015; Milton et al., 2013). However, it may be a presynaptic form of homeostatic plasticity that is analogous to the recognized role of CP-AMPARs in synaptic scaling, a plasticity mechanism important for rebalancing neuronal excitability (Diering and Huganir, 2018). CP-AMPARs preferentially accumulate at synapses after LTP (Turrigiano, 2008; Turrigiano et al., 2014;
Diering and Huganir, 2018) and facilitate synaptic resistance to down-scaling and ubiquitination (Diering et al., 2014; Sanderson et al., 2016). Thus, activation of CB1Rs during memory reconsolidation may be a form of resistance to memory disrupting synaptic upscaling. Future studies will need to investigate whether synaptic scaling is a plasticity mechanism of memory reconsolidation.

AM251 failed to alter drug context-induced cocaine-seeking behavior (Fig. 3) and BLA protein expression $24 \mathrm{~d}$ posttreatment (Fig. $5 N-S$ ), unlike at $3 \mathrm{~d}$ posttreatment (Figs. 1, 5B-G). Such transient amnesia might reflect AM251-induced enhancement of extinction-memory consolidation followed by spontaneous recovery of the cocaine-memory trace (Rescorla, 2004). However, manipulations that enhanced fear extinction-memory consolidation increase GluN2b and reduce BLA Arc expression at test (Alvarez-Dieppa et al., 2016), whereas postretrieval AM251 administration had the opposite effect on these plasticity markers (Fig. 5). Furthermore, a brief cocaine-memory retrieval session is expected to elicit weaker neural activation (Eisenberg et al., 2003) and, therefore, less activity-dependent endocannabinoid mobilization (Castillo et al., 2012) in extinction versus reconsolidation circuits. This may diminish the impact of AM251 as a competitive antagonist, albeit not as an indirect agonist, on extinction consolidation. Alternatively, transient amnesia could reflect AM251-induced interference with the memory "retrieval links" established during consolidation (Lewis et al., 1968; Ramirez et al., 2013; Roy et al., 2016; Richards and Frankland, 2017) instead of memory-reconsolidation interference. A third possibility is that transient amnesia after genuine memoryreconsolidation interference might result from the delayed availability of residual memory traces through prolonged systems consolidation (Nadel and Moscovitch, 1997; Amaral et al., 2008) or reconsolidation prompted by reminders (e.g., resumption of behavioral sessions after extended home-cage stay). Finally, transient amnesia following memory-reconsolidation interference may reflect a time-dependent shift in the mechanisms recruited for the expression of cocaine-seeking behavior. Consistent with this explanation, BLA, dorsomedial prefrontal cortex, or nucleus accumbens neuronal inactivation no longer inhibits cocaineseeking behavior after an extended drug-free period (Fuchs et al., 2006; See et al., 2007).

In conclusion, systemic administration of AM251 in conjunction with re-exposure to a previously cocaine-paired context, a manipulation analogous to exposure therapy, blocks glutamatergic mechanisms associated with memory reconsolidation and transiently alleviates drug context-induced motivation to seek cocaine in a rodent model of drug relapse. Thus, AM251 may provide short-term benefit for individuals with cocaine-use disorders through cognitive and pharmacological mechanisms that are not fully understood. For instance, AM251 is an agonist at GPR55 (CB1 orphan receptor; Kapur et al., 2009) and an antagonist at $\mu$-opioid receptors (Seely et al., 2012) that have been implicated in memory function (Schneider et al., 2014; Kramar et al., 2017). Despite these unknowns, these findings are interesting from a pharmacotherapeutic perspective. Chronic daily treatment with the CB1R inverse agonist, rimonabant, is effective for smoking cessation but produces detrimental side effects (Moreira and Crippa, 2009). Therefore, future studies will need to examine whether less extensive regimens of intermittent postretrieval administration of AM251 or other CB1R antagonists can produce lasting reductions in cue reactivity and cocaine seeking without detrimental side effects. 


\section{References}

Achterberg E, Trezza V, Vanderschuren LJ (2014) Glucocorticoid receptor antagonism disrupts the reconsolidation of social reward-related memories in rats. Behav Pharmacol 25:216-225.

Alaghband Y, O'Dell SJ, Azarnia S, Khalaj AJ, Guzowski JF, Marshall JF (2014) Retrieval-induced NMDA receptor-dependent Arc expression in two models of cocaine-cue memory. Neurobiol Learn Mem 116:79-89.

Alvarez-Dieppa AC, Griffin K, Cavalier S, McIntyre CK (2016) Vagus nerve stimulation enhances extinction of conditioned fear in rats and modulates Arc protein, CaMKII, and GluN2B-containing NMDA receptors in the basolateral amygdala. Neural Plast 2016:4273280.

Amaral OB, Osan R, Roesler R, Tort AB (2008) A synaptic reinforcementbased model for transient amnesia following disruptions of memory consolidation and reconsolidation. Hippocampus 18:584-601.

Arenos JD, Musty RE, Bucci DJ (2006) Blockade of cannabinoid CB1 receptors alters contextual learning and memory. Eur J Pharmacol 539:177183.

Arguello AA, Hodges MA, Wells AM, Lara H, Xie X, Fuchs RA (2014) Involvement of amygdalar protein kinase A, but not calcium/calmodulindependent protein kinase II, in the reconsolidation of cocaine-related contextual memories in rats. Psychopharmacology (Berl) 231:55-65.

Castillo PE, Younts TJ, Chávez AE, Hashimotodani Y (2012) Endocannabinoid signaling and synaptic function. Neuron 76:70-81.

Childress AR, McLellan AT, Ehrman R, O'Brien CP (1988) Classically conditioned responses in opioid and cocaine dependence: a role in relapse. NIDA Res Monogr 84:25-43.

Childress AR, Mozley PD, McElgin W, Fitzgerald J, Reivich M, O’Brien CP (1999) Limbic activation during cue-induced cocaine craving. Am J Psychiatry 156:11-18.

Clem RL, Huganir RL (2010) Calcium-permeable AMPA receptor dynamics mediate fear memory erasure. Science 330:1108-1112.

Crombag HS, Bossert JM, Koya E, Shaham Y (2008) Review. Contextinduced relapse to drug seeking: a review. Philos Trans R Soc Lond B Biol Sci 363:3233-3243.

De Carvalho CR, Pamplona FA, Cruz JS, Takahashi RN (2014) Endocannabinoids underlie reconsolidation of hedonic memories in Wistar rats. Psychopharmacology (Berl) 231:1417-1425.

Diering GH, Huganir RL (2018) The AMPA receptor code of synaptic plasticity. Neuron 100:314-329.

Diering GH, Gustina AS, Huganir RL (2014) PKA-GluA1 coupling via AKAP5 controls AMPA receptor phosphorylation and cell-surface targeting during bidirectional homeostatic plasticity. Neuron 84:790-805.

Eisenberg M, Kobilo T, Berman DE, Dudai Y (2003) Stability of retrieved memory: inverse correlation with trace dominance. Science 301:11021104.

Fang Q, Li FQ, Li YQ, Xue YX, He YY, Liu JF, Lu L, Wang JS (2011) Cannabinoid CB1 receptor antagonist rimonabant disrupts nicotine reward-associated memory in rats. Pharmacol Biochem Behav 99:738742.

Fuchs RA (2006) Different Neural Substrates Mediate Cocaine Seeking after Abstinence versus Extinction Training: A Critical Role for the Dorsolateral Caudate-Putamen. J Neurosci 26:3584-3585.

Fuchs RA, Eaddy JL, Su ZI, Bell GH (2007) Interactions of the basolateral amygdala with the dorsal hippocampus and dorsomedial prefrontal cortex regulate drug context-induced reinstatement of cocaine-seeking in rats. Eur J Neurosci 26:487-498.

Fuchs RA, Bell GH, Ramirez DR, Eaddy JL, Su Z (2009) Basolateral amygdala involvement in memory reconsolidation processes that facilitate drug context-induced cocaine seeking. Eur J Neurosci 30:889-900.

Gobira PH, Aguiar DC, Moreira FA (2013) Effects of compounds that interfere with the endocannabinoid system on behaviors predictive of anxiolytic and panicolytic activities in the elevated T-maze. Pharmacol Biochem Behav 110:33-39.

Hayashi T, Huganir RL (2004) Tyrosine phosphorylation and regulation of the AMPA receptor by Src family tyrosine kinases. J Neurosci 24:61526160.

He K, Song L, Cummings LW, Goldman J, Huganir RL, Lee HK (2009) Stabilization of $\mathrm{Ca} 2+$-permeable AMPA receptors at perisynaptic sites by GluR1-S845 phosphorylation. Proc Natl Acad Sci USA 106:2003320038.

Hearing MC, Schochet TL, See RE, McGinty JF (2010) Context-driven cocaine-seeking in abstinent rats increases activity-regulated gene expression in the basolateral amygdala and dorsal hippocampus differentially following short and long periods of abstinence. Neuroscience 170:570-579.

Hodge J, Bow JP, Plyler KS, Vemuri VK, Wisniecki A, Salamone JD, Makriyannis A, McLaughlin PJ (2008) The cannabinoid CB1 receptor inverse agonist AM 251 and antagonist AM 4113 produce similar effects on the behavioral satiety sequence in rats. Behav Brain Res 193:298-305.

Hong I, Kim J, Kim J, Lee S, Ko HG, Nader K, Kaang BK, Tsien RW, Choi S (2013) AMPA receptor exchange underlies transient memory destabilization on retrieval. Proc Natl Acad Sci USA 110:8218-8223.

Kapur A, Zhao P, Sharir H, Bai Y, Caron MG, Barak LS, Abood ME (2009) Atypical responsiveness of the orphan receptor GPR55 to cannabinoid ligands. J Biol Chem 284:29817-29827.

Kramar C, Loureiro M, Renard J, Laviolette SR (2017) Palmitoylethanolamide modulates GPR55 receptor signaling in the ventral hippocampus to regulate mesolimbic dopamine activity, social interaction, and memory processing. Cannabis Cannabinoid Res 2:8-20.

LeDoux J (2007) The amygdala. Curr Biol 17:868-874

Lee JLC, Everitt BJ, Thomas KL (2004) Independent cellular processes for hippocampal memory consolidation and reconsolidation. Science 304: 839-843.

Lee JLC, Di Ciano P, Thomas KL, Everitt BJ (2005) Disrupting reconsolidation of drug memories reduces cocaine-seeking behavior. Neuron 47:795-801.

Lee JLC, Milton AL, Everitt BJ (2006) Cue-induced cocaine seeking and relapse are reduced by disruption of drug memory reconsolidation. J Neurosci 26:5881-5887.

Lewis DJ, Misanin JR, Miller RR (1968) Recovery of memory following amnesia. Nature 220:704-705.

Li L, Carter J, Gao X, Whitehead J, Tourtellotte WG (2005) The neuroplasticity-associated arc gene is a direct transcriptional target of early growth response (Egr) transcription factors. Mol Cell Biol 25:10286-10300.

Lopez J, Gamache K, Schneider R, Nader K (2015) Memory retrieval requires ongoing protein synthesis and NMDA receptor activity-mediated AMPA receptor trafficking. J Neurosci 35:2465-2475.

Makino H, Malinow R (2009) AMPA receptor incorporation into synapses during LTP: the role of lateral movement and exocytosis. Neuron 64:381-390.

McDonald AJ (1984) Neuronal organization of the lateral and basolateral amygdaloid nuclei in the rat. J Comp Neurol 222:589-606.

McLaughlin PJ, Winston K, Swezey L, Wisniecki A, Aberman J, Tardif DJ, Betz AJ, Ishiwari K, Makriyannis A, Salamone JD (2003) The cannabinoid CB1 antagonists SR 141716A and AM 251 suppress food intake and food-reinforced behavior in a variety of tasks in rats. Behav Pharmacol 14:583-588.

Miller CA, Marshall JF (2005) Molecular substrates for retrieval and reconsolidation of cocaine-associated contextual memory. Neuron 47:873-884.

Milton AL, Lee JLC, Butler VJ, Gardner R, Everitt BJ (2008) Intra-amygdala and systemic antagonism of NMDA receptors prevents the reconsolidation of drug-associated memory and impairs subsequently both novel and previously acquired drug-seeking behaviors. J Neurosci 28:82308237.

Milton AL, Merlo E, Ratano P, Gregory BL, Dumbreck JK, Everitt BJ (2013) Double dissociation of the requirement for GluN2B- and GluN2A-containing NMDA receptors in the destabilization and restabilization of a reconsolidating memory. J Neurosci 33:1109-1115.

Moreira FA, Crippa JAS (2009) The psychiatric side-effects of rimonabant. Braz J Psychiatry 31:145-153.

Nadel L, Moscovitch M (1997) Memory consolidation, retrograde amnesia and the hippocampal complex. Curr Opin Neurobiol 7:217-227.

Nader K, Schafe GE, Le Doux JE (2000) Fear memories require protein synthesis in the amygdala for reconsolidation after retrieval. Nature 406:722-726.

Nakazawa T, Komai S, Watabe AM, Kiyama Y, Fukaya M, Arima-Yoshida F, Horai R, Sudo K, Ebine K, Delawary M, Goto J, Umemori H, Tezuka T, Iwakura Y, Watanabe M, Yamamoto T, Manabe T (2006) NR2B tyrosine phosphorylation modulates fear learning as well as amygdaloid synaptic plasticity. ЕMBO J 25:2867-2877.

National Research Council (2011) Guide for the care and use of laboratory animals, Ed 8. Washington, DC: The National Academies Press.

Ortinski PI, Vassoler FM, Carlson GC, Pierce RC (2012) Temporally dependent changes in cocaine-induced synaptic plasticity in the nucleus 
accumbens shell are reversed by D1-like dopamine receptor stimulation. Neuropsychopharmacology 37:1671-1682.

Ramirez DR, Bell GH, Lasseter HC, Xie X, Traina SA, Fuchs RA (2009) Dorsal hippocampal regulation of memory reconsolidation processes that facilitate drug context-induced cocaine-seeking behavior in rats. Eur J Neurosci 30:901-912.

Ramirez S, Liu X, Lin PA, Suh J, Pignatelli M, Redondo RL, Ryan TJ, Tonegawa S (2013) Creating a false memory in the hippocampus. Science 341:387-391.

Rao-Ruiz P, Rotaru DC, van der Loo RJ, Mansvelder HD, Stiedl O, Smit AB, Spijker S (2011) Retrieval-specific endocytosis of GluA2-AMPARs underlies adaptive reconsolidation of contextual fear. Nat Neurosci 14:13021308.

Rao-Ruiz P, Schmitz LJMM, Smit AB, Spijker S (2015) AMPA receptor plasticity in retrieval, reconsolidation and post-retrieval extinction of memories. In: Novel mechanisms of memory, pp 21-41. Cham: Springer International Publishing.

Rescorla RA (2004) Spontaneous recovery. Learn Mem 11:501-509.

Rich MT, Torregrossa MM (2018) Molecular and synaptic mechanisms regulating drug-associated memories: towards a bidirectional treatment strategy. Brain Res Bull 141:58-71.

Rich MT, Huang YH, Torregrossa MM (2019) Plasticity at thalamo-amygdala synapses regulates cocaine-cue memory formation and extinction. Cell Rep 26:1010-1020.

Richards BA, Frankland PW (2017) The persistence and transience of memory. Neuron 94:1071-1084.

Richardson BD, Rossi DJ (2017) Recreational concentrations of alcohol enhance synaptic inhibition of cerebellar unipolar brush cells via preand postsynaptic mechanisms. J Neurophysiol 118:267-279.

Roy DS, Arons A, Mitchell TI, Pignatelli M, Ryan TJ, Tonegawa S (2016) Memory retrieval by activating engram cells in mouse models of early Alzheimer's disease. Nature 531:508-512.

Sah P, Faber ESL, Lopez De Armentia M, Power J (2003) The amygdaloid complex: anatomy and physiology. Physiol Rev 83:803-834.

Sanderson JL, Gorski JA, Dell'Acqua ML (2016) NMDA receptor-dependent LTD requires transient synaptic incorporation of $\mathrm{Ca}^{2+}$-permeable AMPARs mediated by AKAP150-anchored PKA and calcineurin. Neuron 89:1000-1015.

Schneider AM, Simson PE, Daimon CM, Mrozewski J, Vogt NM, Keefe J, Kirby LG (2014) Stress-dependent opioid and adrenergic modulation of newly retrieved fear memory. Neurobiol Learn Mem 109:1-6.

Schutz-Geschwender A, Zhang Y, Holt T, Mcdermitt D, Olive DM, Biosciences L (2004) Quantitative, two-color Western blot detection with infrared fluorescence. LI-COR Biosci 800:1-8.
See RE, Elliott JC, Feltenstein MW (2007) The role of dorsal vs ventral striatal pathways in cocaine-seeking behavior after prolonged abstinence in rats. Psychopharmacology (Berl) 194:321-331.

Seely KA, Brents LK, Franks LN, Rajasekaran M, Zimmerman SM, Fantegrossi WE, Prather PL (2012) AM-251 and rimonabant act as direct antagonists at mu-opioid receptors: implications for opioid/cannabinoid interaction studies. Neuropharmacology 63:905-915.

Stern CAJ, de Carvalho CR, Bertoglio LJ, Takahashi RN (2018) Effects of cannabinoid drugs on aversive or rewarding drug-associated memory extinction and reconsolidation. Neuroscience 370:62-80.

Stringfield SJ, Higginbotham JA, Wang R, Berger AL, McLaughlin RJ, Fuchs RA (2017) Role of glucocorticoid receptor-mediated mechanisms in cocaine memory enhancement. Neuropharmacology 123:349-358.

Théberge FR, Milton AL, Belin D, Lee JL, Everitt BJ (2010) The basolateral amygdala and nucleus accumbens core mediate dissociable aspects of drug memory reconsolidation. Learn Mem 17:444-453.

Tronson NC, Taylor JR (2007) Molecular mechanisms of memory reconsolidation. Nat Rev Neurosci 8:262-275.

Turrigiano GG (2008) The self-tuning neuron: synaptic scaling of excitatory synapses. Cell 135:422-435.

Turrigiano G, Long t. N, Lüscher C, Malenka RC, Harris KM, Weinberg RJ, Smart TG, Paoletti P, Südhof C (2014) Homeostatic synaptic plasticity: local and global mechanisms for stabilizing. Cell 135:422-435.

Wang H, Treadway T, Covey DP, Cheer JF, Lupica CR (2015) Cocaineinduced endocannabinoid mobilization in the ventral tegmental area. Cell Rep 12:1997-2008.

Wells AM, Lasseter HC, Xie X, Cowhey KE, Reittinger AM, Fuchs RA (2011) Interaction between the basolateral amygdala and dorsal hippocampus is critical for cocaine memory reconsolidation and subsequent drug context-induced cocaine-seeking behavior in rats. Learn Mem 18:693-702.

Wells AM, Arguello AA, Xie X, Blanton MA, Lasseter HC, Reittinger AM, Fuchs RA (2013) Extracellular signal-regulated kinase in the basolateral amygdala, but not the nucleus accumbens core, is critical for context-response-cocaine memory reconsolidation in rats. Neuropsychopharmacology 38:753-762.

Wells AM, Xie X, Higginbotham JA, Arguello AA, Healey KL, Blanton M, Fuchs RA (2016) Contribution of an SFK-mediated signaling pathway in the dorsal hippocampus to cocaine-memory reconsolidation in rats. Neuropsychopharmacology 41:675-685.

Yu LL, Wang XXY, Zhao M, Liu Y, Li YQ, Li FQ, Wang XXY, Xue YX, Lu L (2009) Effects of cannabinoid CB1 receptor antagonist rimonabant in consolidation and reconsolidation of methamphetamine reward memory in mice. Psychopharmacology (Berl) 204:203-211.

Yu YJ, Huang CH, Chang CH, Gean PW (2016) Involvement of protein phosphatases in the destabilization of methamphetamine-associated contextual memory. Learn Mem 23:486-493. 